\title{
Modeling river dune evolution using a parameterization of flow separation
}

\author{
Andries J. Paarlberg, ${ }^{1,2}$ C. Marjolein Dohmen-Janssen, ${ }^{3}$ Suzanne J. M. H. Hulscher, ${ }^{3}$ \\ and Paul Termes ${ }^{1}$ \\ Received 14 September 2007; revised 1 October 2008; accepted 4 November 2008; published 7 February 2009.
}

[1] This paper presents an idealized morphodynamic model to predict river dune evolution. The flow field is solved in a vertical plane assuming hydrostatic pressure conditions. The sediment transport is computed using a Meyer-Peter-Müller type of equation, including gravitational bed slope effects and a critical bed shear stress. To avoid the necessity of modeling the complex flow inside the flow separation zone, we follow an approach similar to one used earlier to simulate the dynamics of wind-blown desert dunes. In case of flow separation, the separation streamline acts as an artificial bed and sediment avalanches down the leeside distributing evenly on the leeside at the angle of repose. Model results show that bed slope effects play a crucial role in the determination of the fastest-growing wavelength from a linear analysis. Flow separation is shown to be crucial to take into account if the dune lee exceeds a certain threshold slope. If flow separation is not included, dune shapes are incorrectly predicted and the dune height saturates at an early stage of bed form evolution, yielding an underprediction of dune height and time to equilibrium. The local bed slope at the dune crest plays a critical role for obtaining an equilibrium dune height. The simulation model is able to predict the main characteristics of dune evolution, such as dune asymmetry, dune growth, and saturation at a certain dune height. Dune dimensions, migration rates, and times to equilibrium compare reasonably well to various data sets.

Citation: Paarlberg, A. J., C. M. Dohmen-Janssen, S. J. M. H. Hulscher, and P. Termes (2009), Modeling river dune evolution using a parameterization of flow separation, J. Geophys. Res., 114, F01014, doi:10.1029/2007JF000910.

\section{Introduction}

[2] Interactions between the flow, the sediment transport and the bed morphology, often lead to the formation of rhythmic patterns on river beds, such as dunes [e.g., Allen, 1968; Ten Brinke et al., 1999; Carling et al., 2000; Parsons et al., 2005]. Because of unidirectional river flows, river dunes migrate in downstream direction and have typical asymmetric shapes. Flow separation in the lee of dunes and associated energy losses, significantly influence flow resistance [e.g., Einstein and Barbarossa, 1952; Engelund, 1966; Vanoni and Hwang, 1967; Wijbenga, 1990; Ogink, 1988; Julien et al., 2002]. For many water management purposes, it is essential to predict the time evolution of river dunes, in order to assess their influence on flow resistance and on water levels.

[3] To analyze the initiation of dunes from flat bed, often linear stability analysis techniques are applied [e.g., Kennedy, 1963; Engelund, 1970; Smith, 1970; Fredsøe, 1974; Richards,

\footnotetext{
${ }^{1} \mathrm{HKV}$ Consultants, Lelystad, Netherlands.

${ }^{2}$ Formerly at Department of Water Engineering and Management, University of Twente, Enschede, Netherlands.

${ }^{3}$ Department of Water Engineering and Management, University of Twente, Enschede, Netherlands.

Copyright 2009 by the American Geophysical Union. 0148-0227/09/2007JF000910\$09.00
}

1980]. Such linear stability models predict whether dunes will, or will not, occur for certain flow conditions. To study the temporal evolution of dunes using stability methods, various attempts have been made to include nonlinear feedback mechanisms between the flow and bed form amplitude [e.g., Ji and Mendoza, 1997; Yamaguchi and Izumi, 2002; Zhou and Mendoza, 2005]. Zhou and Mendoza [2005] derived a nonlinear growth model predicting amplitude growth and saturation of dunes. This perturbation model does not take flow separation into account, while there are several indications that flow separation and associated turbulence and shear layer formation are important for dune morphodynamics [e.g., Sharp, 1963; Nelson et al., 1995; Bennett and Best, 1995; Walker and Nickling, 2002; Sumer et al., 2003].

[4] Only recently, increasing computational power has led to reliable numerical codes to simulate dune evolution by solving coupled systems of flow, sediment transport and bed morphology [Nelson et al., 2005; Tjerry and Fredsøe, 2005; Giri and Shimizu, 2006]. These numerical codes are able to predict the time evolution of dune dimensions, dune shapes and dune migration. The treatment of flow separation and related transport of sediment are key elements in these models, and require complicated flow models that capture not only the mean properties of the flow but also the statistics. Furthermore, such models require an accurate transfer function relating near-bed flow with sediment dynamics. At present, 
the useful application of these numerical codes in water management is still limited, because the models require fast computers and long computational times.

[5] Various approaches have been developed to predict bed form evolution using simplifications regarding solving the flow field. Onda and Hosoda [2004] developed a onedimensional (1-D) numerical model with depth-averaged Boussinesq-type flow equations and hydrostatic pressure, including deceleration and acceleration effects due to flow over wavy beds. Nonhydrostatic effects related to flow separation are incorporated in the friction term. Jerolmack and Mohrig [2005] assumed a nonlinear relationship between the bed topography and the spatial distribution of the bed shear stress over that topography. Both the models of Onda and Hosoda [2004] and Jerolmack and Mohrig [2005] successfully simulated bed form evolution over quite long domains, from initiation to an equilibrium with bed forms of different scales continuously merging and splitting. These models are very useful to yield predictions of dune evolution with limited computational time, but the role of flow separation in dune dynamics could not be captured by these models.

[6] Interestingly, also in other environments bed forms are observed. Wind blown desert dunes and related migration patterns were successfully studied using linear expansions of the flow field, combined with saltation models for grain dynamics [e.g., Kroy et al., 2002; Schwämmle and Herrmann, 2004; Hersen, 2004]. Such an approach could be useful to study the evolution of river dunes as long as they are small compared to the water depth. However, saturated steady state river dunes (i.e., dunes that migrate downstream with an equilibrium dune height) have heights that are typically of the same order as the water depth, meaning that the flow equations have to be solved nonlinearly to reproduce typical flow fields over saturated steady state river dunes.

[7] To predict the time evolution of offshore sand waves, from initial bed disturbances to equilibrium, different nonlinear numerical codes of the Hulscher [1996] model are developed [Van den Berg and Van Damme, 2005; Németh et al., 2006, 2007; Van den Berg, 2007]. These models demonstrated that sand wave formation and saturation toward an equilibrium height is due to circulation cells in the vertical plane, transporting sand from the troughs to the crest of a sand wave, and gravitational bed slope effects counteracting this process. Németh et al. [2006] showed that for unidirectional flows, dune-like sand waves (i.e., asymmetric in flow direction) could be simulated. However, since the used flow model is based on hydrostatic flow equations, separated flows cannot be treated and only small-amplitude sand waves could be studied by Németh et al. [2006].

[8] A similar problem was encountered by Zeman and Jensen [1987] for modeling the complex flow over hills using a linear flow model, which is incapable of simulating reverse flows. To overcome this problem, Zeman and Jensen [1987] suggested to use a separation bubble to represent the flow separation zone. This approach effectively avoids the necessity to simulate the complex flow and sediment transport behavior in this region, and was successfully adopted in several simulation models for aeolian dunes [e.g., Andreotti et al., 2002; Momiji and Bishop, 2002; Kroy et al., 2002; Sauermann et al., 2003].

[9] Our aim is to develop a process-based simulation model of river dune evolution that is useful for operational

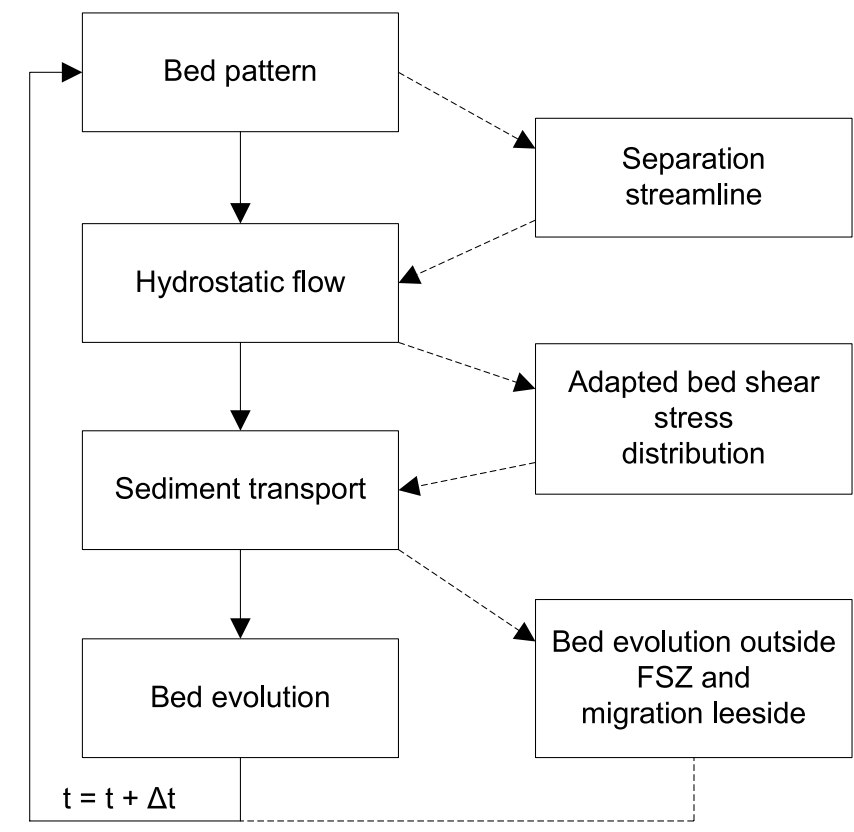

Figure 1. Setup of the morphodynamic model of this paper. The left side of the image (solid arrows) represents the basic morphodynamic cycle, which is followed as long as flow separation does not occur. The right part of the image (dashed arrows) represents the additions related to the parameterization of flow separation (FSZ, flow separation zone).

water management. Such a model should limit the required computational effort. Therefore, we will investigate in this paper, whether the process-based morphodynamic model of Németh et al. [2006] can be extended with a parameterization of flow separation, to enable simulation of finite amplitude river dune evolution. We investigate whether this approach realistically predicts various aspects of river dune evolution, such as dune asymmetry, dune migration and saturation at a certain equilibrium dune height. The role of flow separation will be specifically addressed and relevant parameters and processes that cause bed form growth and saturation are discussed.

[10] The general setup of the morphodynamic simulation model for river dune evolution is presented in Figure 1. The right side of Figure 1 (dashed arrows) represents the additions related to the parameterization of flow separation to the basic morphodynamic cycle (solid arrows). If the bed slope of the dune lee exceeds a certain threshold value, the flow is assumed to separate and the upper boundary of the flow separation zone, the separation streamline, is determined. Using experimental data of flow fields over dunes, Paarlberg et al. [2007] found that the separation streamline over dunes with angle-of-repose slip faces can be approximated by a thirdorder polynomial function, and that the coefficients of that polynomial can be estimated independently of flow conditions. This separation streamline forms a virtual "bed" in the region of flow separation, and the hydrostatic flow over this virtual bed can be computed.

[11] Section 2 presents the flow equations, along with boundary conditions and the parameterization of the separation streamline to compute the flow in case of flow separation. 
The sediment transport and bed evolution equations, both with and without flow separation, are described in section 3. The calibration of model parameters is discussed in section 4 . In section 5 the model results are assessed qualitatively and a quantitative comparison with flume experiments is made. Section 6 presents a discussion on the model and its results and the conclusions are presented in section 7 .

\section{Flow Model}

\subsection{Steady Flow Equations with Hydrostatic Pressure}

[12] The flow is described by the two-dimensional shallow water equations in a vertical plane (i.e., 2-DV), assuming hydrostatic pressure conditions. A scaling analysis of the 2-DV Navier-Stokes equations [e.g., Vreugdenhil, 1994; Paarlberg, 2008] shows that, for small Froude numbers, the momentum equation in vertical direction reduces to the hydrostatic pressure condition, and that the time variations in the horizontal momentum equation can be dropped (i.e., a quasi-steady approach). These approximations are valid for (squared) Froude numbers $\ll 1$, which is the case in mildly sloping rivers. Since Froude numbers for flume conditions are generally larger than in rivers, the model has to be applied with some care to flume conditions. The momentum equation in the $x$ direction and the continuity equation read

$$
\begin{gathered}
u \frac{\partial u}{\partial x}+w \frac{\partial u}{\partial z}=-g \frac{\partial \zeta}{\partial x}+A_{\mathrm{v}} \frac{\partial^{2} u}{\partial z^{2}}+g i \\
\frac{\partial u}{\partial x}+\frac{\partial w}{\partial z}=0
\end{gathered}
$$

[13] The velocities in the $x$ and $z$ directions (Figure 2) are $u$ and $w$, respectively. The water surface elevation is denoted by $\zeta, i$ is the average channel slope, and $g$ and $A_{\mathrm{v}}$ denote the acceleration due to gravity and the vertical eddy viscosity, respectively. In equation (1) the terms on the left-hand side are advective terms, and on the right-hand side the terms represent a pressure gradient, turbulent diffusion and gravity force due to a sloping bed (Figure 2), respectively.

\subsection{Boundary Conditions}

[14] The boundary conditions at the water surface $(z=h)$ are (1) no flow through the surface and (2) no shear stress at the surface:

$$
\begin{aligned}
& u \frac{\partial \zeta}{\partial x}=w \\
& \frac{\partial u}{\partial z}=0
\end{aligned}
$$

[15] The kinematic boundary condition at the bed $\left(z=z_{\mathrm{b}}\right)$ is that there is no flow through the boundary:

$$
u \frac{\partial z_{\mathrm{b}}}{\partial x}=w
$$

[16] As basic turbulence closure, we use a $z$-independent eddy viscosity, leading to a parabolic velocity profile [e.g., Hulscher, 1996]. To correctly represent the bed shear stress

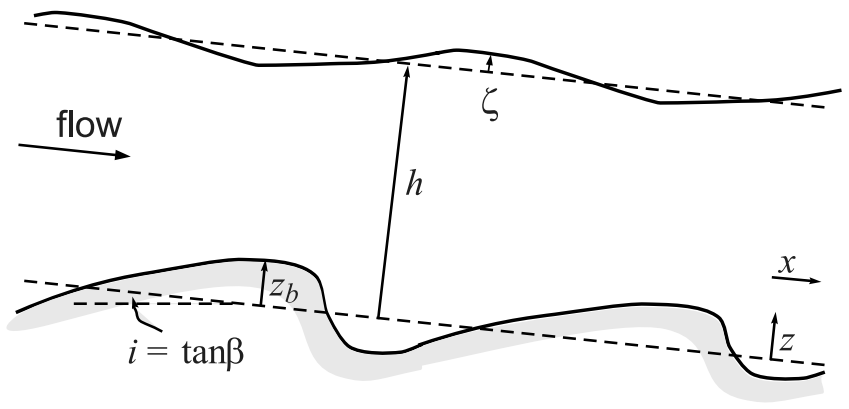

Figure 2. Definitions of the average flow depth $h$, the bed elevation $z_{\mathrm{b}}$, the water surface elevation $\zeta$, and the channel slope $i$. In the given coordinate system, $x$ is the streamwise coordinate and $z$ is the vertical coordinate.

for a constant eddy viscosity, we need a partial slip condition at the bed $\left(z=z_{\mathrm{b}}\right)$ :

$$
\tau_{\mathrm{b}}=A_{\mathrm{v}} \frac{\partial u}{\partial z}=S u_{\mathrm{b}}
$$

where $\tau_{\mathrm{b}}$ is the volumetric bed shear stress (i.e., shear stress divided by water density) $\left(\mathrm{m}^{2} \mathrm{~s}^{-2}\right)$, and the resistance parameter $S\left(\mathrm{~m} \mathrm{~s}^{-1}\right)$ controls the resistance at the bed [Hulscher and van den Brink, 2001; Besio et al., 2004]. Soulsby [1990] showed that a constant eddy viscosity over the flow depth, in combination with a partial slip condition at the bed, results in a good representation of the vertical flow structure and the bed shear stress. Furthermore, a partial slip condition was previously successfully applied to tidal flows [e.g., Prandle, 1982; Maas and Van Haren, 1987; Schramkowski and de Swart, 2002]. For open channel flows, Engelund [1970] used a bed boundary condition similar to a partial slip condition, by allowing for a horizontal velocity at the bed. Relationships for the eddy viscosity $A_{\mathrm{v}}$ and resistance parameter $S$ will be determined in section 4 .

[17] In this paper we choose to use periodic boundary conditions, requiring an additional equation to guarantee uniqueness of the solution:

$$
\int_{0}^{L_{\mathrm{dom}}} \zeta d x=0
$$

where $L_{\text {dom }}$ is the length of the periodic domain. A rigid lid approximation is used at the water surface. For details about the numerical solution procedure for the flow equations, see Van den Berg and Van Damme [2005] and Van den Berg [2007].

[18] In the present paper, we employ periodic boundary conditions (both for the flow and the sediment transport modules). The channel slope (Figure 2 and term "gi" in equation (1)) is the driving force for the flow, meaning that the (specific) discharge is not specified in the model, but follows inherently from the solution of the equations. The main parameters that control this discharge are the eddy viscosity and bed resistance parameter. Apart from two calibration coefficients that will be specified later (section 4), these parameters only depend on the channel slope and the water 
depth. If the dune height increases for both a constant channel slope and water depth, the simulated specific discharge decreases. This is not in line with flume experiments where the constant discharge is accompanied by an increasing water depth due to increasing bed roughness. Therefore, in model simulations, the average flow depth $h$ is changed iteratively such that the specific discharge found as solution of the flow equations equals that of the experiment (within $1 \%$ accuracy).

\subsection{Flow Separation Criterion}

[19] Sinusoidal bed forms of low amplitude do not necessarily cause the flow to separate. However, if the amplitude of a sinusoidal bed form grows and it becomes asymmetrically shaped in downstream direction, leeside slopes increase so that the flow eventually separates. To include this in the morphodynamic model, we define a critical leeside slope; if this critical slope is exceeded, flow separation is taken into account in a parameterized way (Figure 1).

[20] Best and Kostaschuk [2002] used measurements over low-angle dunes to show that intermittent (i.e., nonpermanent) flow separation occurs over dunes with maximum lower leeside slopes of $-14^{\circ}$. At present, the dynamics of flow over low-angle dunes, and under which conditions they form is not yet fully known [Best, 2005], and it is therefore not possible to state at which exact leeside slope the flow will separate. Azad [1996] reports intermittent flow separation to occur downstream from conical diffusers, in which the change in angle at the diffuser expansion is often less than $10^{\circ}$ [Best, 2005]. Detailed (numerical) analysis of flow over different leeside slopes should give more insight on this aspect for dunes.

[21] In this paper, we choose to use a critical leeside slope of $-10^{\circ}$, meaning that flow separation is not modeled for dunes with leeside slopes milder than $-10^{\circ}$. Thus, intermittent flow separation is not taken into account; once the lee slope criterion is exceeded, the flow separation zone is considered to be permanent. The sensitivity to the choice of critical leeside slope is investigated in a sensitivity analysis in section 5.5.

\subsection{Parameterization of the Separation Streamline}

[22] Figure 3 shows the typical shape of a flow separation zone over a dune with a fully developed angle-of-repose lee face. The flow separates at the dune crest (which is equal to the brinkpoint in this case), and a reattachment zone is located approximately 5 dune heights downstream of the dune crest [Paarlberg et al., 2007]. A separation streamline can be identified which forms the upper boundary of the flow separation zone. Paarlberg et al. [2007] determined the separation streamline $s$ (Figure 3), and thus the shape of the flow separation zone, using experimental data of turbulent flow over subaqueous dunes as a third-order polynomial. Paarlberg et al. [2007] showed that the coefficients of this polynomial can be estimated, independently of flow conditions, on the basis of the dune shape at the flow separation point and a fixed angle of the separation streamline at the flow reattachment point.

[23] Following Kroy et al. [2002], the hydrostatic flow is computed by using the separation streamline $s$ as artificial bed and the flow within the flow separation zone is not explicitly treated. The applied partial slip condition over a
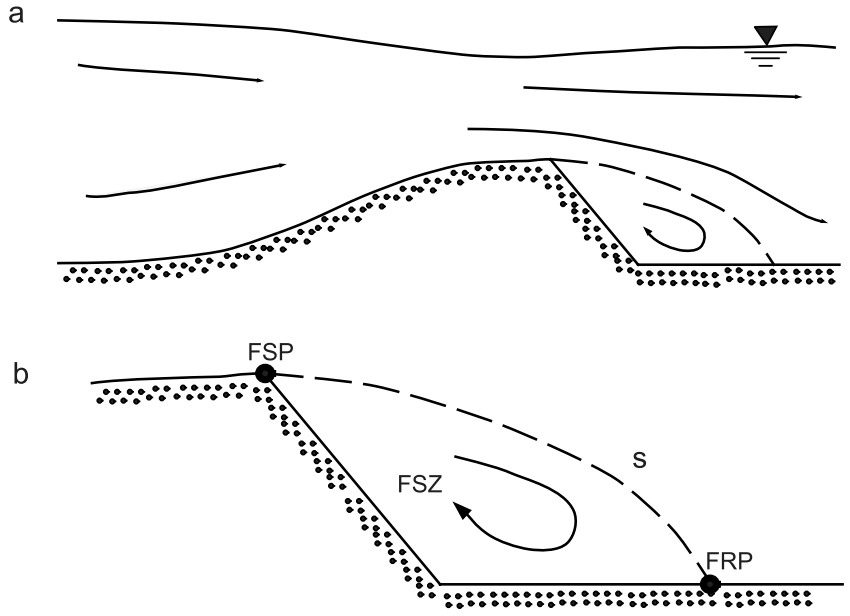

Figure 3. Schematic representation of flow separation in the dune lee. (a) Flow over a complete dune. (b) Detail of the flow separation zone (FSZ). The dashed line is the separation streamline (s), with the flow separating at the flow separation point (FSP) and reattaching at an angle to the bed at the flow reattachment point (FRP).

the separation streamline equals the one over the bed. This is a simplification of reality regarding the flow field and turbulence and shear layer formation associated with flow separation. However, we are mainly interested in the morphological behavior rather than solving all details of the flow field.

\section{Sediment Transport and Bed Evolution Model 3.1. Bed Load Transport Formula Including Bed Slope Effects}

[24] In cases where bed load transport is dominant, dunes are asymmetrically shaped with a leeside slope at approximately the angle of repose $\left(\sim-30^{\circ}\right)$ [Smith and McLean, 1977; Kostaschuk and Villard, 1996]. In the present paper, we do not incorporate suspended sediment transport, as this is regarded not crucial in modeling river dune formation and migration in bed load dominated rivers. For relatively large Froude numbers or Shields numbers, the influence of suspended sediment transport is significant. Using a numerical analysis, Tjerry and Fredsøe [2005] showed that at relatively high Shields numbers, dunes tend to get longer and more symmetrically shaped if most of the sediment is transported in suspension. Engelund [1970] showed that suspended sediment transport is especially important in supercritical flow regimes with Froude numbers close to or exceeding 1. In the flume experiments considered in this paper, Froude numbers are generally in the order of $0.3-0.5$, and for field conditions the numbers are often even smaller, meaning that the effects of suspended sediment transport can be safely neglected.

[25] The local bed load transport rate is evaluated using the turbulence-averaged bed shear stress as obtained with equation (6). Although this approach neglects transport details associated with turbulence fluctuations of the bed shear stress [Nelson et al., 1995], it enables to study temporal dune evolution. In this paper, we apply the sediment transport 
formula of Meyer-Peter and Müller [1948], including gravitational bed slope effects:

$$
q_{b}=\left\{\begin{array}{lll}
\alpha\left(\tau(x)-\tau_{\mathrm{c}}(x)\right)^{n}\left(1+\eta \frac{\partial z_{\mathrm{b}}}{\partial x}\right)^{-1} & \text { if } & \tau>\tau_{\mathrm{c}} \\
0 & \text { if } & \tau \leq \tau_{\mathrm{c}}
\end{array}\right.
$$

in which $\tau$ is the bed shear stress $\left(\mathrm{m}^{2} \mathrm{~s}^{-2}\right)$ and $\tau_{\mathrm{c}}$ a critical bed shear stress. The proportionality constant $\alpha\left(\mathrm{s}^{2} \mathrm{~m}^{-1}\right)$ describes how efficiently the sand particles are transported by the bed shear stress [Van Rijn, 1993] and strongly determines the timescale of bed evolution. Its value can be estimated with

$$
\alpha=\frac{m}{\left(\rho_{\mathrm{s}} / \rho-1\right) g}
$$

where $\rho_{\mathrm{s}} / \rho$ is the specific grain density $(=2.65)$, and $m$ is an empirical coefficient. The bed slope parameter $\eta$ reflects the downhill preference of moving sediment and is inversely related to the tangent of the angle of repose $\varphi$ [e.g., Sekine and Parker, 1992]:

$$
\eta=\frac{1}{\tan (\varphi)}
$$

We will show that the gravitational bed slope effects are important to determine the fastest-growing wavelength using linear analysis (section 4), and for saturation at an equilibrium dune height (section 5.3). In fluvial systems, the bed shear stress is often of the same order as the critical bed shear stress. Moreover, it is influenced by bed slope effects [Fredsøe and Deigaard, 1992, p. 205]. The critical bed shear stress $\left(\tau_{\mathrm{c}}\right)$ is corrected for bed slope effects using the following expression:

$$
\tau_{\mathrm{c}}(x)=\tau_{\mathrm{c} 0} \frac{1+\eta \frac{\partial z_{\mathrm{b}}}{\partial x}}{\sqrt{1+\frac{\partial z_{\mathrm{b}}^{2}}{\partial x}}}
$$

with $\tau_{\mathrm{c} 0}$ the critical bed shear stress for flat bed, defined as

$$
\tau_{\mathrm{c} 0}=\theta_{\mathrm{c} 0} g\left(\rho_{\mathrm{s}} / \rho-1\right) D_{50}
$$

in which $\theta_{\mathrm{c} 0}$ is the critical Shields parameter and $D_{50}$ is the median grain size $(\mathrm{m})$.

[26] On the basis of flume experiments, Meyer-Peter and Müller [1948] suggested a value of 8 for the empirical coefficient $m$ and a critical Shields number of 0.047 . A recent reanalysis performed by Wong and Parker [2006], using the data of Meyer-Peter and Müller [1948] and additional data, revealed that the coefficients as proposed by Meyer-Peter and Müller [1948] yield an overprediction of the sediment transport rate by a factor of 2.0-2.5. Wong and Parker [2006] obtained a better fit using $m=4$ and a critical Shields number of 0.05 , which are the values that are applied in the present paper.

\subsection{Bed Shear Stress Distribution in Case of Flow Separation}

[27] Correct modeling of the bed shear stress distribution over dunes is crucial, since it directly determines the local sediment transport rate (equation (8)), and thus dune evolution. In case of flow separation, the hydrostatic flow is computed over the parameterized bed $z_{\mathrm{p}}$ (dotted line in Figure $4 \mathrm{c}$ ), yielding the bed shear stress distribution over the dunes (dotted line in Figure 4b). Measurements of bed shear stresses [Raudkivi, 1963; Vittal, 1972; McLean et al., 1994; Coleman et al., 2006], normalized by the maximum bed shear stress for that experiment (Figure 4a), show that in the flow separation zone the turbulence-averaged bed shear stress reduces to zero. Therefore, in our simulation model, the bed shear stress is set to zero within the flow separation zone (horizontal solid lines in Figure $4 \mathrm{~b}$ ), yielding zero sediment transport rates. This procedure yields two discontinuities in the bed shear stress distribution over a dune, i.e., at the flow separation point and at the flow reattachment point. The discontinuity at the flow separation point will be resolved in section 3.3.

[28] To overcome the discontinuity at the flow reattachment point we need a parameterization of the bed shear stress distribution over the stoss side of the dunes. Figure 4a shows bed shear stresses derived from measurements of flow over fixed dunes. Although bed shear stresses are difficult to obtain, especially in the vicinity of the flow separation and reattachment zone, Figure 4a shows that downstream of the reattachment point, the bed shear stress gradually increases from zero to a maximum value toward the crest of the downstream dune. To mimic this behavior, the bed shear stress distribution over a dune in case of flow separation is parameterized as $\tau_{\mathrm{p}}$, using a third-order polynomial function:

$$
\tau_{\mathrm{p}}(x)=\left\{\begin{array}{lll}
0 & \text { if } & x_{\mathrm{s}}<x \leq x_{\mathrm{r}}(\mathrm{FSZ}) \\
a_{3} x^{\prime 3}+a_{2} x^{2} & & \\
+a_{1} x^{\prime}+a_{0} & \text { if } & x_{\mathrm{r}} \leq x \leq x_{\mathrm{m}}(\text { stoss side) }
\end{array}\right.
$$

in which $x_{\mathrm{s}}$ is the flow separation point, $x_{\mathrm{r}}$ the reattachment point, $x_{\mathrm{m}}$ the $x$ coordinate of the maximum bed shear stress, $x^{\prime}=x-x_{\mathrm{r}}$, and $a_{0} \ldots a_{3}$ are coefficients.

[29] In case of flow separation, no critical bed shear stress is apparent near reattachment, because of the large turbulent fluctuations in the reattachment zone. However, further downstream on the stoss side a critical bed shear stress does exist. To apply the sediment transport relationship (equation (8)) continuously without and with flow separation, we include the critical bed shear stress also in case of flow separation. The most transparent manner to obtain this behavior is to (1) set the bed shear stress to the critical bed shear stress at the flow reattachment point, effectively yielding a zero transport rate at that point and (2) impose a positive gradient at the flow reattachment point to ensure sediment transport from the flow reattachment point in downstream direction. Therefore, coefficient $a_{0}$ equals the critical bed shear stress at the flow reattachment point $\left(\tau_{\mathrm{r}}\right)$, and coefficient $a_{1}$ is specified as

$$
a_{1}=\left.\frac{d \tau_{\mathrm{p}}}{d x}\right|_{x_{\mathrm{r}}}=\tau_{\mathrm{A}} \frac{\tau_{\mathrm{m}}-\tau_{\mathrm{r}}}{x_{\mathrm{m}}-x_{\mathrm{r}}}
$$

The parameter $\tau_{\mathrm{A}}$ is estimated from the measurements as $\tau_{\mathrm{A}}=2$. This means that the gradient in the bed shear stress at the flow reattachment point is twice the average shear stress gradient between $x_{\mathrm{r}}$ and $x_{\mathrm{m}}$. This choice of $\tau_{\mathrm{A}}$ reflects the observation that a lot of sediment is transported at the 

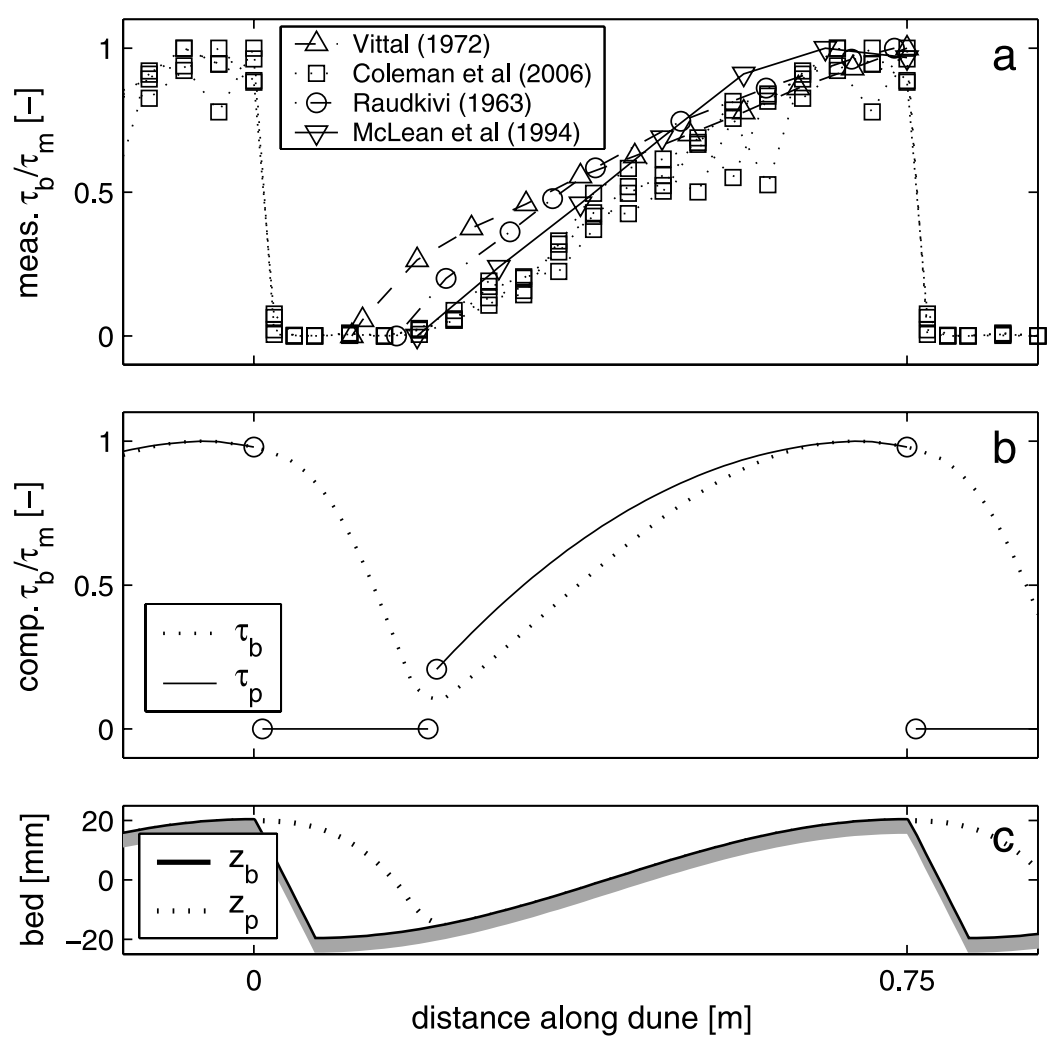

Figure 4. Illustration of the procedure to parameterize the bed shear stress distribution over a dune in case of flow separation. (a) Measured bed shear stresses, normalized by the maximum measured bed shear stress for that case $\left(\tau_{\mathrm{m}}\right)$. (b) Computed bed shear stress $\tau_{\mathrm{b}}$ over the parameterized bed $z_{\mathrm{p}}$ and parameterized bed shear stress $\tau_{\mathrm{p}}$ according to equation (13). Circles represent the discontinuities as discussed in the text. (c) Bed level $z_{\mathrm{b}}$ and parameterized bed level $z_{\mathrm{p}}$.

flow reattachment point, mainly as a result of turbulence generated in the flow reattachment zone [e.g., Sumer et al., 2003; Tjerry and Fredsøe, 2005].

[30] Classical theories on dune formation show that phase shifts between the bed topography and the bed shear stress are crucial for modeling dune morphology. The maximum bed shear stress $\left(\tau_{\mathrm{m}}\right)$ often occurs upstream of the dune crest because of fluid inertia. To take this effect into account in equation (13), the coefficients $a_{2}$ and $a_{3}$ are set by imposing a smooth connection to the bed shear stress (and gradient in bed shear stress) at $x_{\mathrm{m}}$, which are computed over the parameterized bed $\left(z_{\mathrm{p}}\right)$. The solid line in Figure $4 \mathrm{~b}$ gives a typical example of the parameterized bed shear stress in case of flow separation, which compares reasonably well to the measurements presented in Figure 4a.

\subsection{Bed Evolution}

[31] Without flow separation, topographic changes follow from the Exner equation, using the sediment transport rate computed with equation (8):

$$
\left(1-\epsilon_{\mathrm{p}}\right) \frac{\partial z_{\mathrm{b}}}{\partial t}=-\frac{\partial q_{\mathrm{b}}}{\partial x}
$$

where $\epsilon_{\mathrm{p}}$ is the bed porosity (typically $\epsilon_{\mathrm{p}} \sim 0.4$ ).

[32] In case of flow separation, the bed shear stress distribution follows from equation (13) and the evolution of the stoss side of a dune can simply be solved using the continuity equation (15). As was mentioned in section 3.2, the sediment transport rate is zero within the flow separation zone. The volumetric sediment transport passing the flow separation point is assumed to settle quickly in the flow separation zone and avalanches down the lee face where it distributes evenly (Figure 5a). The leeside slope is assumed constant and equal to the angle of repose for submerged natural sand, which is about $-30^{\circ}$.

[33] Flow separation sets in if the leeside slope of a dune exceeds a threshold of $-10^{\circ}$ (section 2.3). This means that there is a discrepancy between this bed slope and the angle of repose when flow separation sets in. To overcome this discrepancy, the leeside builds up from the bed form crest under the angle of repose, ensuring sediment continuity (Figure 5b). In this way, a fully developed leeside at the angle of repose, with a region of permanent flow separation, typically develops within 10 time steps in the model. Using this approach, we have constructed a model that is able to compute the evolution of a dune from a case without separation to a case with flow separation, continuously.

[34] The bottom update is done using explicit forward Euler time integration and in equation (8) both $z_{\mathrm{b}}$ and $\tau_{\mathrm{b}}$ are treated explicitly. Figure $5 \mathrm{~b}$ shows that in one time step, the bed is horizontally extended from the separation point to the point where the lee slope starts. In reality this will be a more "curved" process. Therefore the bed is smoothed at the flow separation point over 5 grid points before the flow is computed (a dune typically covers 120 grid points in 


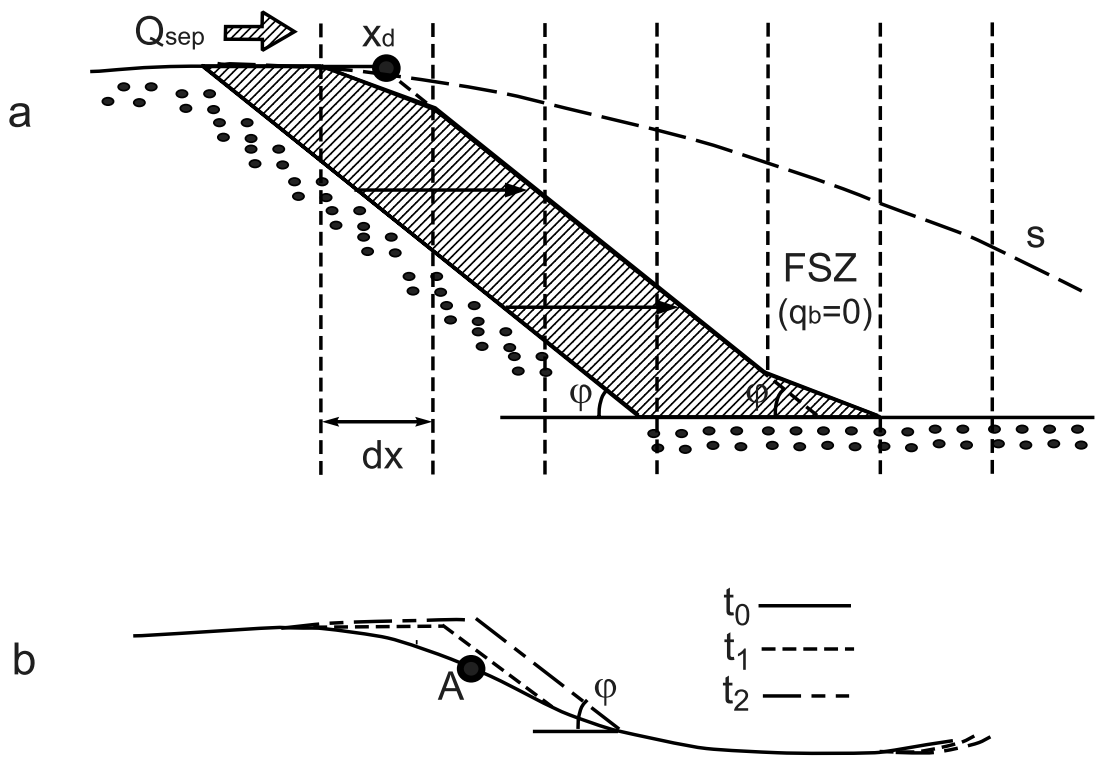

Figure 5. Illustration of the sediment transport and bed evolution in case of flow separation. (a) The volume of sediment that passes the flow separation point during one time step $\left(Q_{\text {sep }}\right)$ distributes evenly over the leeside, with the leeside at the angle of repose $(\varphi)$. Here $x_{\mathrm{d}}$ is the horizontal position where the leeside starts; $\mathrm{dx}$ is the horizontal grid distance. (b) If flow separation starts to occur (i.e., if $\mathrm{d} z_{\mathrm{b}} / \mathrm{d} x=-10^{\circ}$ at position $\mathrm{A}$ ), the leeside builds at the angle of repose from the dune crest, with $t_{0} \ldots t_{2}$ indicating successive time steps.

horizontal direction). Since the parameterized separation streamline reattaches to the bed at a certain angle (Figure 3b), also at the reattachment point the bed is smoothed over 5 grid points. Both smoothing algorithms are for 5 points, which is the minimal required number of points to prevent numerical instabilities in the flow solver.

\section{Parameter Settings and Calibration of the Partial Slip Model}

[35] The general and numerical parameters that are required to perform simulations, are presented in Table 1. The grid spacing in both horizontal and vertical direction is equidistant. Sufficient resolution in vertical direction is required to resolve the flow recirculation cells as discussed by Hulscher and Dohmen-Janssen [2005].

[36] In uniform and steady open channel flows, the eddy viscosity profile over the flow depth can be described by a parabolic profile [see, e.g., Fredsøe and Deigaard, 1992]. Integration of such a profile over the flow depth gives a relationship for the depth-averaged eddy viscosity:

$$
A_{\mathrm{v}} \sim \frac{1}{6} \kappa u_{*} h
$$

in which $\kappa$ is the Von Kármán constant $(=0.407)$, and $u *$ is the shear velocity $(=\sqrt{g h i})$. Note that this equation is similar to the one used by Engelund [1970]. Several authors have related the resistance parameter $S$ to the shear velocity [Engelund, 1970; Maas and Van Haren, 1987; Zhou and Mendoza, 2005]:

$$
S \sim u_{*}
$$

Since we use periodic boundary conditions in the morphodynamic model, we cannot specify the discharge as model forcing (section 2.2). Therefore, calibration of $S$ and $A_{\mathrm{v}}$ has to result in a correct discharge for the simulation, and to this end $S$ and $A_{\mathrm{v}}$ are specified as

$$
A_{\mathrm{v}}=\beta_{1} \frac{1}{6} \kappa u_{*} h
$$

and

$$
S=\beta_{2} u_{*}
$$

where $\beta_{1}$ and $\beta_{2}$ are calibration coefficients.

[37] For a flat bed, the equation of motion (equation (1)) reduces to

$$
0=A_{\mathrm{v}} \frac{\partial^{2} u}{\partial z^{2}}+g i
$$

and can be solved analytically to obtain the specific discharge $q$ using boundary conditions (4) and (6) (the kine-

Table 1. General Parameters for a Model Run

\begin{tabular}{lccc}
\hline \multicolumn{1}{c}{ Parameter } & Symbol & Value & Dimension \\
\hline Acceleration of gravity & $g$ & 9.81 & $\mathrm{~m} \mathrm{~s}^{-2}$ \\
Proportionality constant & $m$ & 4 & - \\
Nonlinearity parameter & $n$ & 1.5 & - \\
Specific grain density & $\rho_{\mathrm{s}} / \rho$ & 2.65 & - \\
Sediment porosity & $\epsilon_{\mathrm{p}}$ & 0.4 & - \\
Critical shields parameter & $\theta_{c 0}$ & 0.05 & - \\
Angle of repose & $\varphi$ & 30 & $\mathrm{deg}$ \\
Grid points in $x$ direction & $\mathrm{Npx}$ & 120 & - \\
Grid points in $z$ direction & $\mathrm{Npz}$ & 25 & - \\
Time step flow solver & $\mathrm{dt}$ & 1 & $\mathrm{~s}$ \\
\hline
\end{tabular}




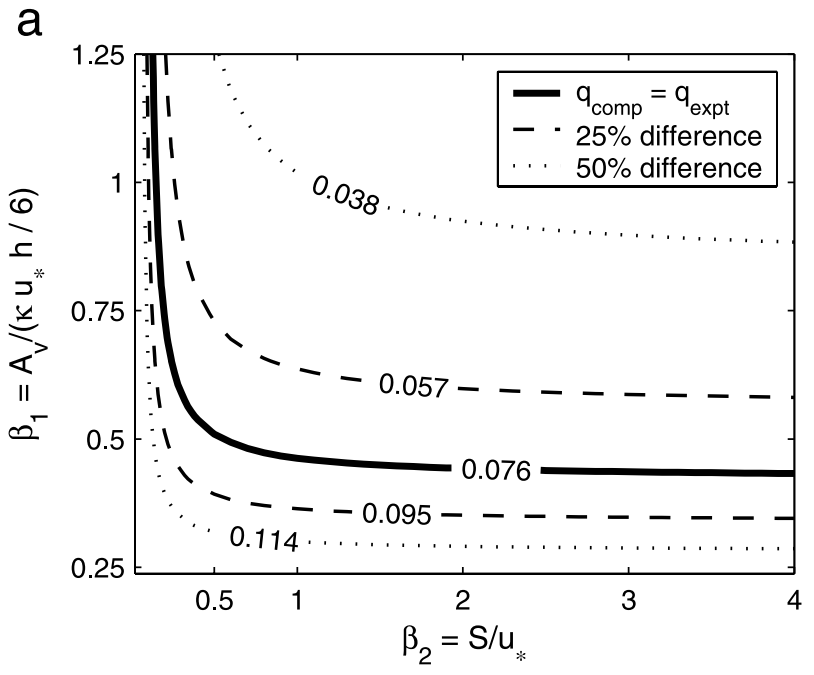

b

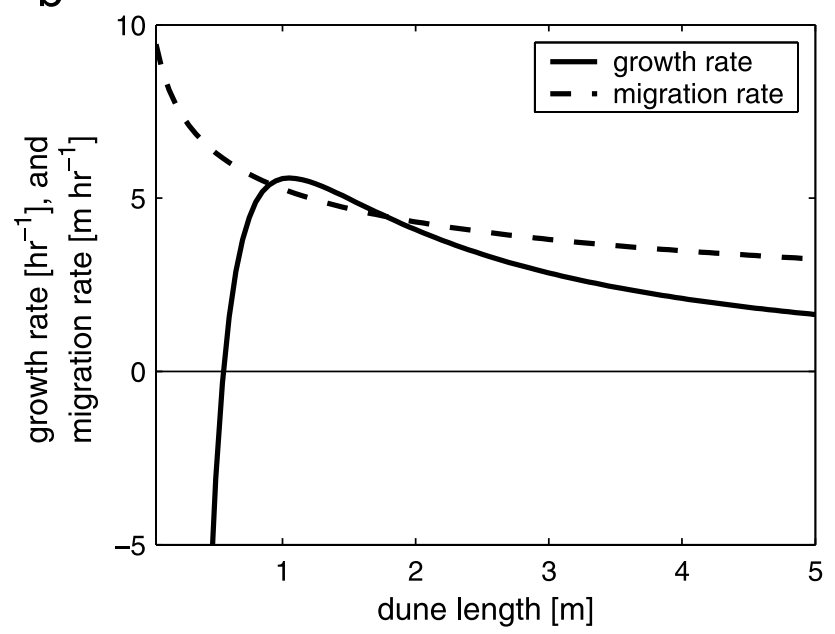

Figure 6. Calibration of the partial slip model using flow A of Venditti et al. [2005]. (a) Simulated flow over a flat rough bed, represented as the computed specific discharge $q_{\text {comp }}\left(\mathrm{m}^{2} \mathrm{~s}^{-1}\right)$, for various values of the calibration coefficients $\beta_{1}$ and $\beta_{2}$, compared to the discharge in the experiment $q_{\text {expt. }}$ (b) Linear stability plot for $\beta_{1}=\beta_{2}=0.5$, showing growth and migration rate curves in the linear regime.

matic boundary conditions are not relevant in case of a flat bed, because there are no gradients in $x$ direction):

$$
q=U h=\frac{u_{*}^{2} h\left(h S+3 A_{\mathrm{v}}\right)}{3 A_{\mathrm{v}} S}=\frac{2 u_{*} h\left(\beta_{2}+\frac{1}{2} \beta_{1} \kappa\right)}{\beta_{1} \beta_{2} \kappa}
$$

where $U$ is the depth-averaged flow velocity. The coefficients $\beta_{1}$ and $\beta_{2}$ are calibrated using flow A as reported in [Venditti et al., 2005], where the initial water depth $h=0.153 \mathrm{~m}$, the flume slope $i=0.0012$, the specific discharge $q=0.076 \mathrm{~m}^{2} \mathrm{~s}^{-1}$, and the median grain size $D_{50}=0.50 \mathrm{~mm}$. Figure $6 \mathrm{a}$ shows the computed specific discharge (equation (21)) for different values of $\beta_{1}$ and $\beta_{2}$, and the solid line represents the specific discharge that was measured by Venditti et al. [2005] for this specific experiment. Various combinations of $\beta_{1}$ and $\beta_{2}$ yield the measured specific discharge. The simulated discharge is largely insensitive for the value of $\beta_{2}$ if $\beta_{2}>=0.5$. In this paper we choose to use $\beta_{1}=\beta_{2}=0.5$, which gives $U=11.8 u *$ (equation (21)). Using the widely applied Chézy equation, this yields a Chézy coefficient of $37 \mathrm{~m}^{1 / 2} \mathrm{~s}^{-1}$, which is a quite common value for flume experiments with sandy beds [e.g., Blom et al., 2003].

[38] Figure 6b shows a stability plot for $\beta_{1}=\beta_{2}=0.5$, obtained from a numerical linear stability analysis, assuming sinusoidal bed forms and no flow separation (see Dodd et al. [2003] for details on stability theory). The fastest-growing wavelength is $\sim 1.05 \mathrm{~m}$, with a migration rate of about $5 \mathrm{~m} \mathrm{~h}^{-1}$. In their experiments, Venditti et al. [2005] found initial migration rates of $5-15 \mathrm{~m} \mathrm{~h}^{-1}$, and Venditti [2003] reports a wavelength in equilibrium of $\sim 1.17 \mathrm{~m}$. By assuming that the wavelength found using a linear analysis, is representative for the wavelength in steady state equilibrium, this supports our choice for the coefficients $\beta_{1}$ and $\beta_{2}$.

[39] Local sediment fluxes are not exactly in phase with the bed shear stress, since local bed slopes influence the sediment transport rate (equation (8)). Effectively, this means that the maximum sediment flux does not necessarily occur at the dune crest. This effect is crucial to determine the fastestgrowing wavelength, as is illustrated in Figure 7. Fluid inertia causes a displacement between the position of the maximum bed shear stress with respect to the dune crest $\left(\delta_{\tau}\right)$. This displacement is always negative with respect to the dune crest because of fluid inertia, and increases for increasing dune lengths because the inertial effects increase with dune length (Figure 7). However, the displacement between the maximum flux and the dune crest $\left(\delta_{q}\right)$, can also be positive because of local bed slope effects. Short sinusoidal bed forms can only grow in amplitude, if an upstream (negative) displacement exists between the top of the bed profile and the position of maximum sediment flux over the bed form $\left(\delta_{\mathrm{q}}\right)$ [e.g., Kroy et al., 2002; Charru, 2006]. Figure 7 shows that in our model the displacement $\delta_{\mathrm{q}}$ is positive for shorter dunes causing them to decay.

\section{Model Results}

\subsection{Flow Field Structure}

[40] The residual time-independent flow field calculated with the model (Figure 8a) shows that the water motion has

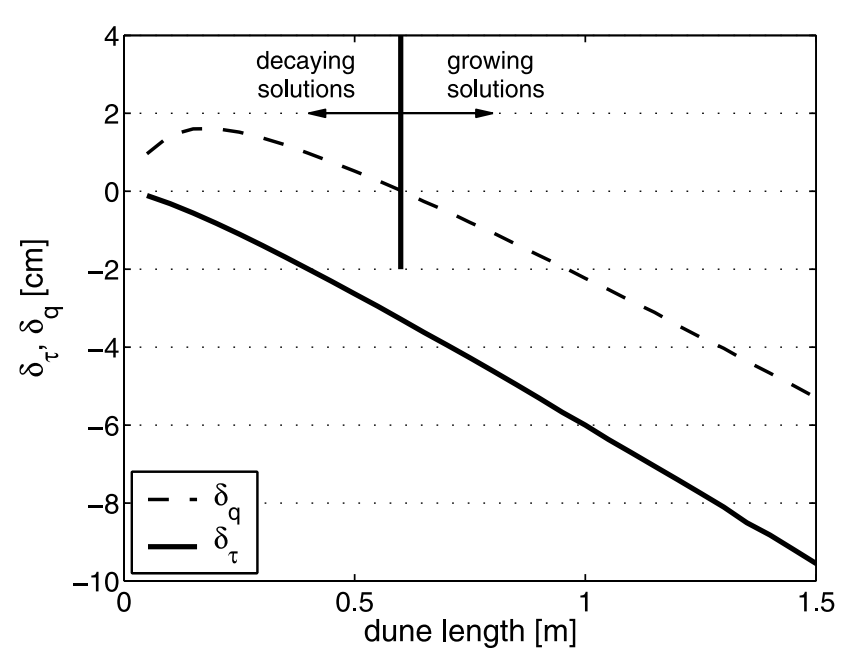

Figure 7. Displacement distances between maximum shear stress $\left(\delta_{\tau}\right)$ and maximum sand flux $\left(\delta_{q}\right)$ with respect to the top of a dune profile as a function of dune length. 

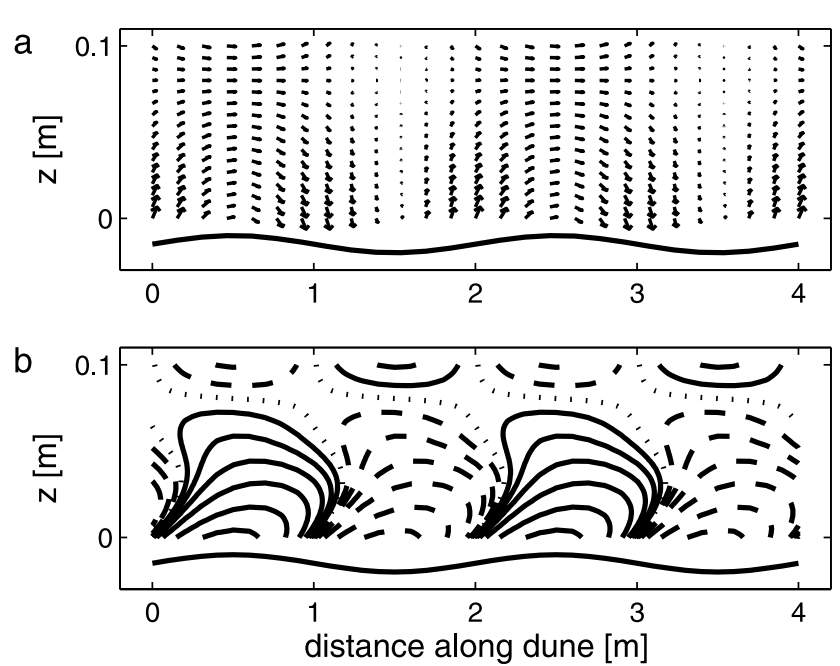

Figure 8. Flow response to a small bed disturbance consisting of two identical dunes (sketched at bottom). (a) Residual time-independent flow field. (b) Vorticity $\left(V=\frac{\partial u}{\partial z}-\frac{\partial w}{\partial x}\right)$, indicating $V=0$ (dotted lines), $V>0$ (solid lines), and $V<0$ (dashed lines). On the vertical axis is the vertical coordinate, and on the horizontal axis is the streamwise coordinate. Unidirectional flow is from left to right.

a circulation pattern with residual velocities oriented toward the crest. This means that sediment is picked up at the stoss side of a dune and is deposited at the leeside, giving rise to the migration of dunes. In his classical work on bed instability, Engelund [1970] showed that transport of vorticity in the flow field plays an important role in dune formation. Figure $8 \mathrm{~b}$ illustrates that vorticity is transported downstream, with clear circulation patterns present. The circulation cells found with the present model are similar to those found for offshore sand waves generated in tidal flows [Hulscher, 1996; Németh et al., 2007].

\subsection{General Model Behavior}

[41] Figure 9 shows the temporal dune evolution for a setting similar to flow A of Venditti et al. [2005]. Every line shows a bed profile, with a time interval of $5 \mathrm{~min}$. The initial

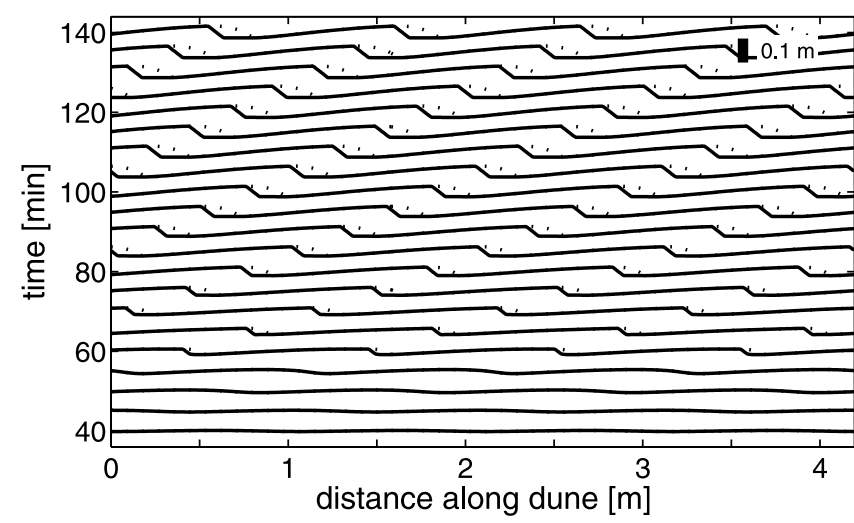

Figure 9. Dune evolution for a simulation of flow A of Venditti et al. [2005]. Every line represents a bed profile, with a time interval of $5 \mathrm{~min}$. Dotted lines represent the separation streamlines at the top of the flow separation zone.
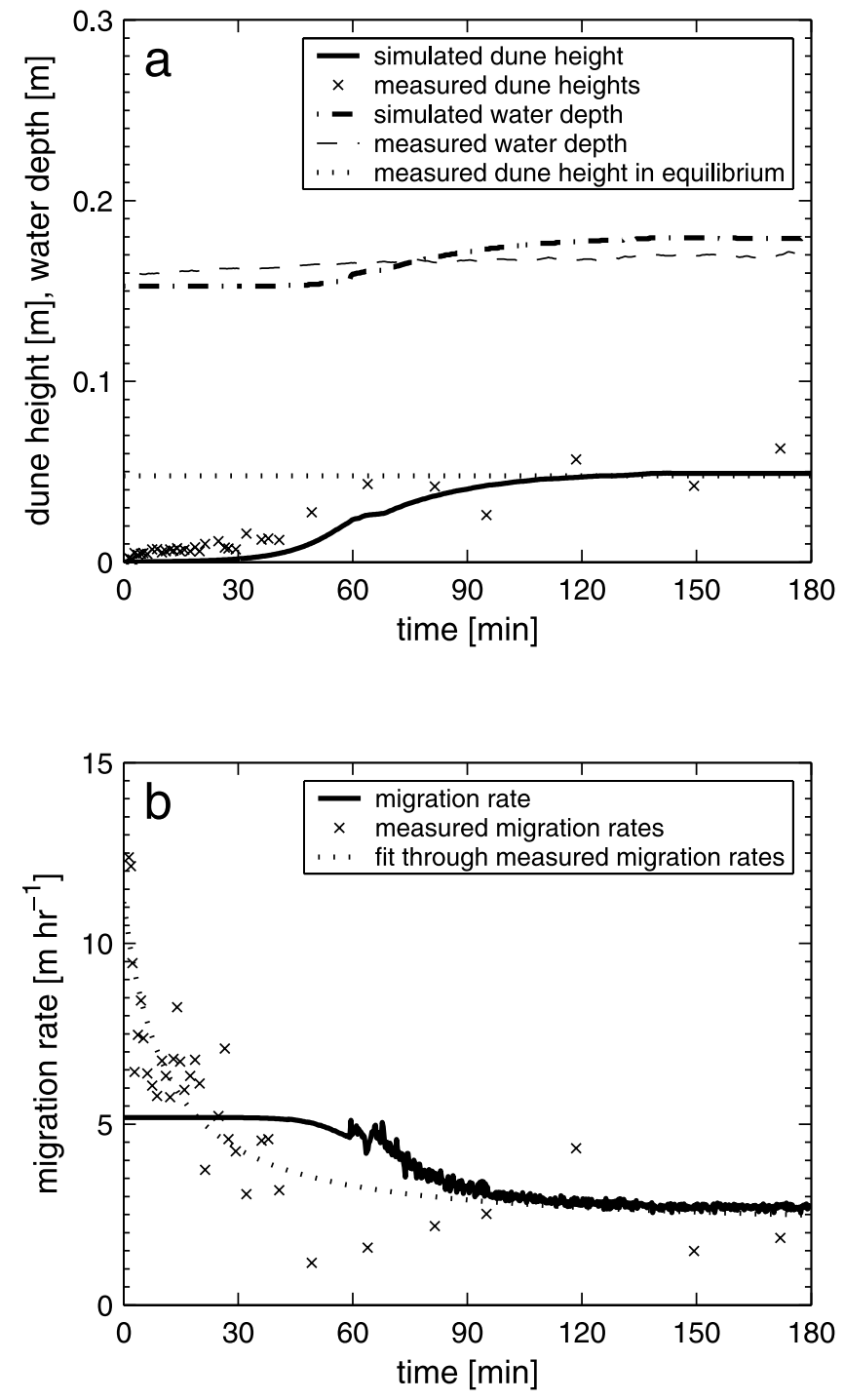

Figure 10. Simulation results for flow A of Venditti et al. [2005]. (a) Comparison of simulated and measured dune height and water depth. (b) Comparison of simulated and measured migration rate (fit is from Venditti [2003]). The dune height is defined as the vertical distance between the crest and its successive trough. The migration rate is based on the phase difference of the Fourier transform between two successive bed profiles.

bed topography consists of a symmetrical sinusoidal wave with initial dune height $\Delta_{\mathrm{i}}=0.1 D_{50}$. The dune length is constant during a simulation and is obtained from a numerical linear stability analysis (Figure 6b). Initially the bed forms remain more or less symmetrical and the bed form height slowly increases. For larger amplitudes, nonlinear effects become more pronounced and the sinusoidal bed forms become asymmetrical with steeper sloping leesides. After about an hour, the flow starts to separate and the leeside builds up following the angle of repose (as illustrated in Figure 5).

[42] The temporal evolution of some characteristic parameters is shown in Figure 10. Figure 10a shows that the dune height (defined as the vertical distance between a crest and its downstream trough) initially increases slowly, which is because local bed slopes are small. During evolution, the 
dunes get more asymmetrically shaped and grow in amplitude (Figure 9), leading to a steeper growth curve. Because of the increased dune height, and thus increased bed roughness, also the water depth increases during a simulation (Figure 10a). The dunes attain an equilibrium where the dune height and water depth remain constant, while the dunes still migrate in downstream direction without changing shape (Figure 9). Measurements of water depth and dune height are included in Figure 10a showing good agreement in equilibrium.

[43] The time to equilibrium is determined independently of the initial bed form amplitude by defining it as the time it takes for a dune to develop from dune height $\Delta=0.05 \Delta_{\mathrm{e}}$ to $\Delta=0.95 \Delta_{\mathrm{e}}$, where $\Delta_{\mathrm{e}}$ is the equilibrium dune height. The equilibrium dune height is defined such that the dune height remains constant over at least 50 computational time steps. Applying this criterion of the time to equilibrium to Venditti's [2003] data gives a time to equilibrium of $\sim 1.5 \mathrm{~h}$. For our simulations, the time to equilibrium is $\sim 1.4 \mathrm{~h}$ (Figure 10). Apparently, the model estimates this characteristic timescale very well.

[44] The migration rate of simulated dunes is determined on the basis of the phase shift between the Fourier transforms of two successive bed topographies. The model simulations show that initially, when the dunes are still low, the migration rate is $\sim 5 \mathrm{~m} \mathrm{~h}^{-1}$. In equilibrium, the migration rate is $\sim 2.7 \mathrm{~m}$ $\mathrm{h}^{-1}$, which is in very good agreement with the value found by Venditti et al. [2005] (Figure 10b). Comparing Figures 10a and $10 \mathrm{~b}$, shows that the migration rate is inversely proportional to the dune height, as was already suggested by Exner [1920] and later by, e.g., Niño et al. [2002]. Similarly, Andreotti et al. [2002] found the inverse of the migration velocity of aeolian dunes to scale with its size.

[45] The discrepancies between simulated and observed dune heights and migration rates are largest in the initial phase of dune formation. Also, the pattern by which the equilibrium water depth is obtained is not in line with the experiment: it shows a similar curve as the evolution of dune height, while in the experiment the water depth increases more steadily. It is important to realize that in our simulations the dune length is constant. However, in the experiments, the initial dune length is small and in combination with a small amplitude, these small and relatively steep dunes can migrate quickly and already create drag in the initial stage of dune formation. This initial phase is not captured by our model leading to the observed discrepancies.

\subsection{Processes Related to Growth and Saturation}

[46] In this section we analyze dune growth and saturation toward an equilibrium dune height for both a case without and with flow separation included, to analyze whether flow separation changes dune evolution. Figure 11 shows the parameters that play a role in the growth and saturation dynamics for the same simulation as presented in section 5.2.

[47] First we analyze the case without taking flow separation into account, although the dune lee gets steeper than the criterion of $-10^{\circ}$. In section 4 it was shown that bed forms grow in amplitude, if an upstream displacement exists between the dune crest and the position of maximum sediment flux $\left(\delta_{\mathrm{q}}\right)$, since this causes deposition at the dune crest. For the first 70 min of dune formation, the upstream displacement of $\delta_{\mathrm{q}}$ (Figure 11a) indeed causes deposition at the dune crest
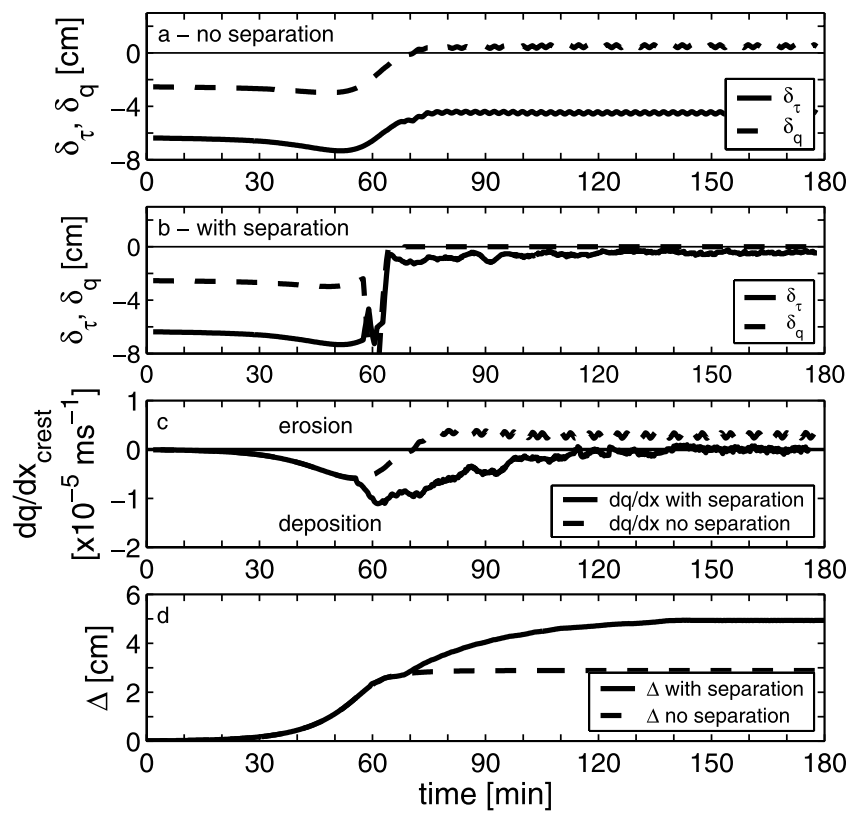

Figure 11. Parameters that play a role in the growth and saturation dynamics of a dune. (a) Displacements between maximum shear stress $\left(\delta_{\tau}\right)$ and maximum sand flux $\left(\delta_{q}\right)$ with respect to the dune crest without flow separation included. (b) The same displacements for a case with flow separation included. (c) Erosion (positive) and deposition (negative) at the dune crest. (d) Dune height evolution.

(Figure 11c), yielding dune growth (Figure 11d). After about an hour, a marked decrease of the displacement $\delta_{\tau}$ is observed (Figure 11a); that is, the position of the maximum stress shifts closer to the dune crest. As a result, after about $70 \mathrm{~min}$, the displacement $\delta_{\mathrm{q}}$ shifts slightly downstream of the crest. This causes a delicate balance between erosion at the dune crest (Figure 11c) and deposition just downstream of the dune crest (not shown), yielding a dune that migrates downstream with constant dune height. Effectively, the dune amplitude saturates to an equilibrium quite abruptly (Figure 11d) if the maximum lee slope that develops is about $-18^{\circ}$, i.e., just after the moment that flow separation is expected to become important.

[48] Now we analyze a simulation taking flow separation into account. For this case, the displacements $\delta_{\tau}$ and $\delta_{\mathrm{q}}$ are presented in Figure 11b. After about an hour, flow separation sets in, indicated by the sharp changes in displacements. Both displacements vanish almost completely, if the dune crest reaches the slip face after about 65 minutes. In case of flow separation, the flow is computed over the separation streamline in the region of flow separation. The local bed slope at the flow separation point, which is not necessarily zero, is important in the determination of the shape of the separation streamline [Paarlberg et al., 2007]. A positive slope at the dune crest, yields a downstream displacement of the top of the artificial bed over which the flow is computed. This causes the displacement between the bed shear stress and the dune crest $\left(\delta_{\tau}\right)$ to reduce to almost zero; that is, it comes closer to the dune crest (Figure 11b). Because of bed slope effects, the displacement $\delta_{\mathrm{q}}$ seems to vanish completely (Figure 11b), which would imply vanishing deposition at the dune crest. 
Table 2. Experimental Conditions and Reported Dune Characteristics for the Validation Experiments Used in This Paper

\begin{tabular}{|c|c|c|c|c|c|c|c|c|c|c|c|c|}
\hline \multirow[b]{2}{*}{ Author $^{\mathrm{a}}$} & \multicolumn{7}{|c|}{ Experimental Conditions } & \multicolumn{5}{|c|}{ Measured Dune Characteristics } \\
\hline & $b(\mathrm{~m})$ & $h_{\mathrm{i}}(\mathrm{m})$ & $i\left(\times 10^{-4}\right)$ & $q\left(\mathrm{~m}^{2} \mathrm{~s}^{-1}\right)$ & $U\left(\mathrm{~m} \mathrm{~s}^{-1}\right)$ & $\mathrm{Fr}$ & $D_{50}(\mathrm{~mm})$ & $\lambda_{\mathrm{e}}(\mathrm{m})$ & $\Delta_{\mathrm{e}}(\mathrm{m})$ & $h_{\mathrm{e}}(\mathrm{m})$ & $T_{\mathrm{e}}(\mathrm{h})$ & $M_{\mathrm{e}}\left(\mathrm{m} \mathrm{h}^{-1}\right)$ \\
\hline VA & 1.00 & 0.152 & 12.0 & 0.077 & 0.51 & 0.42 & 0.50 & 1.172 & 0.048 & 0.17 & 1.5 & 2.7 \\
\hline VB & 1.00 & 0.152 & 11.0 & 0.074 & 0.49 & 0.40 & 0.50 & 0.860 & 0.042 & 0.17 & 1.5 & 1.8 \\
\hline $\mathrm{VC}$ & 1.00 & 0.153 & 7.0 & 0.060 & 0.39 & 0.32 & 0.50 & 0.954 & 0.036 & 0.17 & 1.5 & 1.4 \\
\hline VD & 1.00 & 0.153 & 5.5 & 0.053 & 0.34 & 0.28 & 0.50 & 0.954 & 0.036 & 0.17 & 1.5 & 0.8 \\
\hline $\mathrm{C} 1 \mathrm{M}$ & 0.44 & 0.135 & 18.0 & 0.079 & 0.59 & 0.51 & 0.74 & 0.558 & 0.025 & $\mathrm{n} / \mathrm{a}$ & 0.5 & $\mathrm{n} / \mathrm{a}$ \\
\hline $\mathrm{C} 2 \mathrm{Ma}$ & 1.50 & 0.170 & 20.9 & 0.120 & 0.71 & 0.55 & 0.82 & 0.544 & 0.040 & $\mathrm{n} / \mathrm{a}$ & 1.0 & $\mathrm{n} / \mathrm{a}$ \\
\hline $\mathrm{C} 2 \mathrm{Mb}$ & 1.50 & 0.100 & 27.8 & 0.063 & 0.63 & 0.63 & 0.82 & 0.718 & 0.041 & $\mathrm{n} / \mathrm{a}$ & 0.4 & $\mathrm{n} / \mathrm{a}$ \\
\hline F12 & 1.50 & 0.101 & 32.8 & 0.069 & 0.68 & 0.69 & 0.77 & 1.116 & 0.060 & 0.12 & $\mathrm{n} / \mathrm{a}$ & $\mathrm{n} / \mathrm{a}$ \\
\hline F14 & 1.50 & 0.106 & 10.6 & 0.042 & 0.40 & 0.39 & 0.77 & 1.732 & 0.051 & 0.11 & $\mathrm{n} / \mathrm{a}$ & $\mathrm{n} / \mathrm{a}$ \\
\hline F18 & 1.50 & 0.493 & 25.9 & 0.662 & 1.34 & 0.61 & 0.77 & 1.760 & 0.147 & 0.49 & $\mathrm{n} / \mathrm{a}$ & $\mathrm{n} / \mathrm{a}$ \\
\hline GS1 & 0.10 & 0.052 & 20.0 & 0.020 & 0.38 & 0.54 & 0.28 & 0.240 & 0.025 & 0.07 & $\mathrm{n} / \mathrm{a}$ & 0.3 \\
\hline GS2 & 0.10 & 0.083 & 20.0 & 0.040 & 0.48 & 0.54 & 0.28 & 0.290 & 0.025 & 0.10 & $\mathrm{n} / \mathrm{a}$ & 4.8 \\
\hline GS3 & 0.10 & 0.108 & 20.0 & 0.060 & 0.55 & 0.54 & 0.28 & 0.480 & 0.030 & 0.12 & $\mathrm{n} / \mathrm{a}$ & 7.8 \\
\hline GS4 & 0.10 & 0.131 & 20.0 & 0.080 & 0.61 & 0.54 & 0.28 & 0.650 & 0.030 & 0.15 & $\mathrm{n} / \mathrm{a}$ & 10.5 \\
\hline GS5 & 0.10 & 0.152 & 20.0 & 0.100 & 0.66 & 0.54 & 0.28 & 0.700 & 0.035 & 0.17 & $\mathrm{n} / \mathrm{a}$ & 15.8 \\
\hline A22 & 0.44 & 0.150 & 15.0 & 0.085 & 0.56 & 0.46 & 0.85 & 0.670 & 0.041 & 0.19 & 1.0 & 2.6 \\
\hline A23 & 0.44 & 0.125 & 15.0 & 0.064 & 0.51 & 0.46 & 0.85 & 0.690 & 0.036 & 0.16 & 1.0 & 2.3 \\
\hline $\mathrm{A} 24$ & 0.44 & 0.100 & 15.0 & 0.046 & 0.46 & 0.46 & 0.85 & 0.600 & 0.032 & 0.13 & 1.5 & 1.6 \\
\hline
\end{tabular}

${ }^{a}$ First letters: V is Venditti et al. [2005]; C is Coleman et al. [2005]; F is Fuonza measurements, reported by Driegen [1986]; GS is Giri and Shimizu [2006]; A is Auckland measurements, reported by Friedrich et al. [2007]. Other identifiers refer to numbers used by authors. Here $b=$ flume width, $h_{\mathrm{i}}=$ initial water depth, $i=$ flume slope, $q=$ specific discharge, $U=$ depth-averaged flow velocity, $\mathrm{Fr}=$ Froude number, $D_{50}=$ median grain size, $\lambda_{\mathrm{e}}=$ equilibrium dune length, $\Delta_{\mathrm{e}}$ = equilibrium dune height, $h_{\mathrm{e}}=$ equilibrium water depth, $T_{\mathrm{e}}=$ time to equilibrium, and $M_{\mathrm{e}}=$ migration rate in equilibrium. Here n/a means not available.

[49] However, careful analysis of the displacement $\delta_{\mathrm{q}}$ reveals small upstream displacements, which are actually smaller than the horizontal grid distance. In case of flow separation, the bed shear stress distribution is parameterized over the stoss side of a dune. This yields a relatively large sediment flux convergence at the dune crest, yielding deposition at the dune crest (Figures 11c and 11d). This deposition process continues for about an hour, until the displacement $\delta_{\mathrm{q}}$ vanishes completely and an equilibrium dune height is obtained after about $140 \mathrm{~min}$. From this analysis, it is clear that the local bed slope plays a crucial role in the saturation to an equilibrium dune height, since it determines (1) the shape of the separation streamline, (2) the bed shear stress distribution and thus the displacement $\delta_{\tau}$, and (3) the displacement $\delta_{\mathrm{q}}$. In this simulation, an equilibrium dune height is obtained if the local bed slope at the dune crest is about $1.5^{\circ}$. It can be concluded that because of the separation streamline, the shear stress maximum shifts downstream such that it eventually reaches the dune crest and selects the dune amplitude.

\subsection{Comparison With Various Data Sets}

[50] Up to now, the discussion of the model focused on one experimental condition. In this section, the model performance is tested quantitatively, by simulating different experiments reported in literature, for which the experimental conditions are listed in Table 2. In Table 2, the measured dune dimensions, water depths, migration rates in equilibrium and the times to equilibrium are presented. If available, the measurements are taken from the cited literature, but it is not always clear how they are determined. Dune dimensions are often determined using subjective criteria [Van der Mark et al., 2007; Friedrich et al., 2007]. The migration rate of a train of bed forms is difficult to assess, since every bed form has its own migration rate, and some average has to be taken.

[51] The experiments of Giri and Shimizu [2006] start from a flat bed, for which the initial water depth is not reported. Therefore, the initial flow depth as given in Table 2 is estimated by assuming steady flow over the flat bed, and choosing the flow depth such that the reported discharge is obtained in the calculations. Note that for the experiments of Giri and Shimizu [2006], the Froude number is the same for all considered cases. For the experiments of Coleman et al. [2005], the average water depth in equilibrium is not available, neither is the migration rate. Coleman et al. [2005] report times to equilibrium.

[52] Figure 12 shows the comparison between measured and simulated dune characteristics, where Figures $12 \mathrm{a}-12 \mathrm{f}$ concern values in equilibrium. Simulated initial dune lengths are determined from a (numerical) linear stability analysis for the specific experimental conditions in each case; after that, the dune length remains constant during a simulation. Figures $12 \mathrm{a}-12 \mathrm{c}$ compare computed and observed dune heights, dune lengths and dune aspect ratios, respectively. Overall, the dune dimensions are predicted reasonably well, with most of the experiments between the $25 \%$ accuracy bands. The observation that the equilibrium dune length is predicted reasonably well (Figure 12b), illustrates that the dune length found from a linear analysis is a reasonable estimate for the dune length in equilibrium. The simulated equilibrium dune heights are generally $\sim 33 \%$ of the initial average water depth $h_{\mathrm{i}}$, and $\sim 28 \%$ of the equilibrium average water depth $h_{\mathrm{e}}$, which is well in range with values found in literature.

[53] The dune aspect ratio is important for roughness predictions, considering that the equilibrium roughness predictor of for instance Van Rijn [1984] incorporates the dune aspect ratio as an important parameter. Since for a considerable number of cases the dune length is $10-30 \%$ overestimated, the dune aspect ratio is generally underpredicted. It seems that the dune aspect ratio is predicted, independently of flow conditions, at $\sim 0.045$, meaning that the dune length and dune height are linked. This observation will be analyzed further in section 5.5.

[54] Figures $12 \mathrm{~d}$ and $12 \mathrm{e}$ show that the migration rate and time to equilibrium compare reasonably well, although limited data are available. It is remarkable that the migration 
(a) dune height $\Delta[\mathrm{m}]$

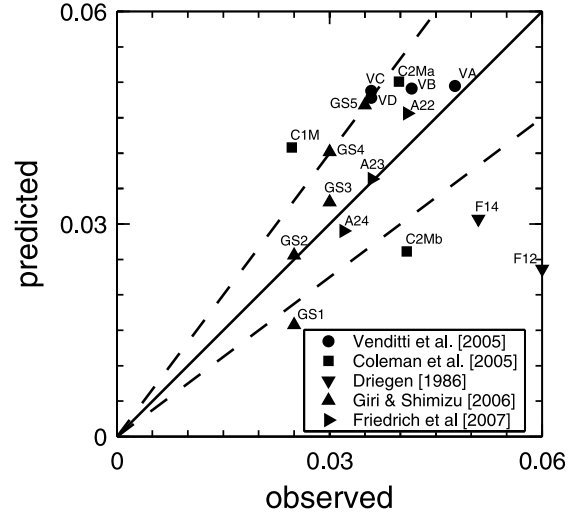

(d) migration rate $\mathrm{M}\left[\mathrm{m} \mathrm{hr}^{-1}\right]$

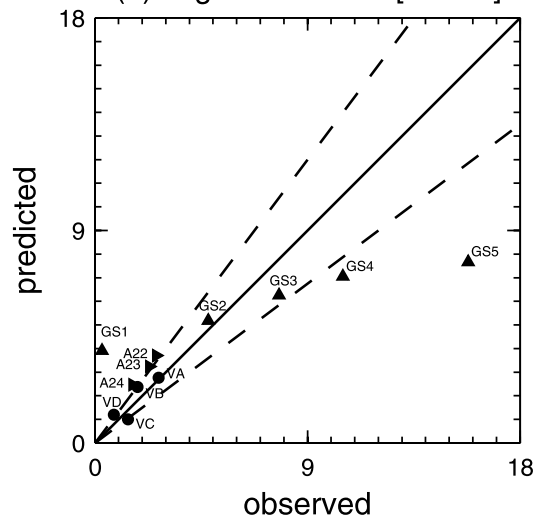

(b) dune length $\lambda[\mathrm{m}]$

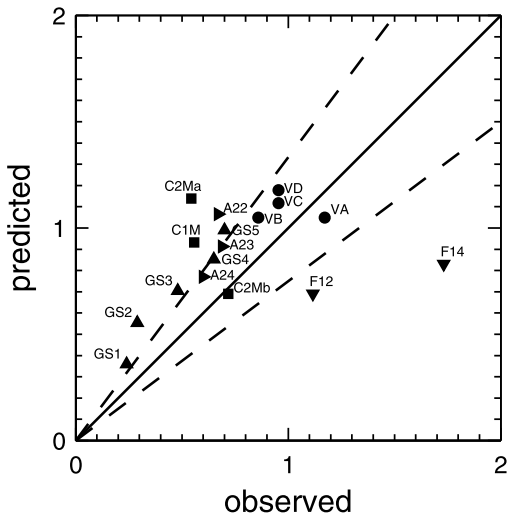

(e) time to equilibrium $\mathrm{T}[\mathrm{hr}]$

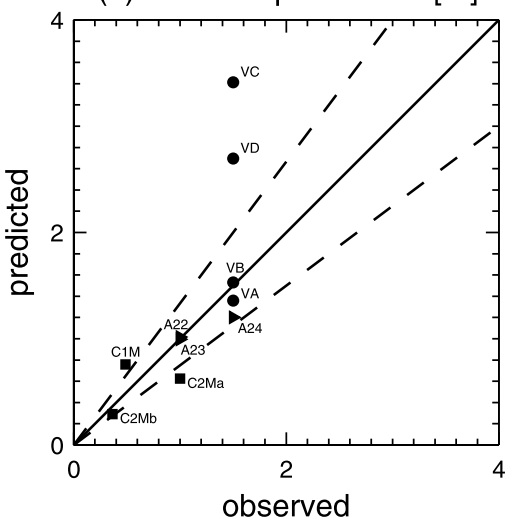

(c) dune aspect ratio $\Delta / \lambda[-]$

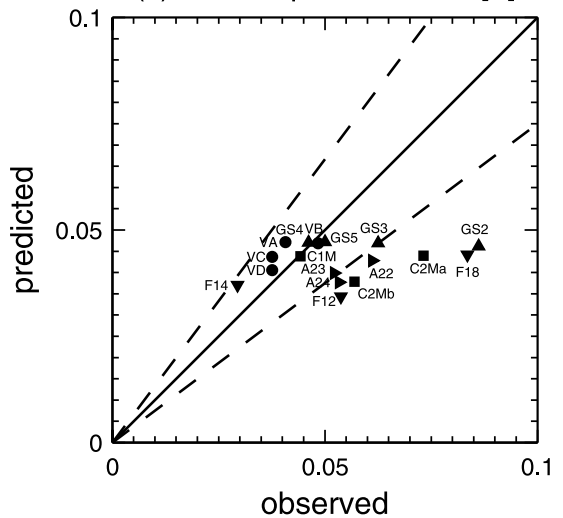

(f) water depth $\mathrm{h}[\mathrm{m}]$

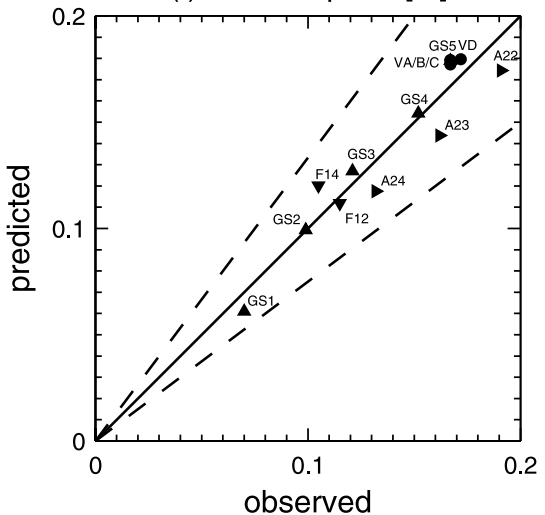

Figure 12. Comparison of simulated (vertical axis) and observed (horizontal axis) dune characteristics in equilibrium: (a) dune height, (b) dune length, (c) dune aspect ratio, (d) migration rate, (e) time to equilibrium, and (f) water depth. Dashed lines indicate the $25 \%$ accuracy band. Experimental conditions can be found in Table 2 .

rate is not predicted correctly for both the lowest and the highest flow strength of the experiment of Giri and Shimizu [2006], which might be related to the relatively small flume width in their experiments. Figure $12 \mathrm{f}$ shows the comparison between observed and computed average water depths in equilibrium. The agreement is excellent, meaning that the simulation model gives a good estimate of flow resistance and energy losses in the flow separation zone.

\subsection{Sensitivity Analysis}

[55] In this section we analyze the effect of the calibration parameters for the partial slip model and deviations from the fastest-growing wavelength as initial dune length on dune evolution. Also, we investigate how various flow and sediment transport parameters affect dune dimensions and timescales of dune evolution (i.e., migration rate and time to equilibrium). The simulation as presented in section 5.2 serves as reference case for the sensitivity analysis (i.e., on the basis of flow A of Venditti et al. [2005]).

[56] Since the parameters of the partial slip model are partly based on a calibration (using coefficients $\beta_{1}$ and $\beta_{2}$ ), variations of these coefficients might have large implications for the simulation results. Case 1 in Table 3 analyzes the effects of changes in the values of these coefficients. The four combinations of $\beta_{1}$ and $\beta_{2}$ are all on the solid thick line in Figure $6 \mathrm{a}$, yielding a correct discharge in the simulations.
Table 3 shows that for the cases $1 \mathrm{c}$ and $1 \mathrm{~d}$, the higher resistance at the bed (i.e., higher values of $\beta_{2}$ compared to the reference situation, "ref" in Table 3 ) yields shorter fastestgrowing wavelengths. Times to equilibrium substantially decrease and dune aspect ratios increase with respect to the reference situation. For the long wave in case 1a, it takes very long for an equilibrium to be obtained as a result of the low growth rate for this length.

[57] For the remainder of this sensitivity analysis, we focus on the case $\beta_{1}=\beta_{2}=0.5$. Case 2 in Table 3 analyzes the effect of deviations from the fastest-growing wavelength. (Thus in a simulation the dune length is not equal to the fastest-growing wavelength as determined from a stability analysis, but is altered according to the numbers in Table 3). A 40\% shorter dune (case $2 \mathrm{a}$ ) yields a situation without flow separation, because of a very small growth rate of the dune. The other cases show that the dune aspect ratio is the same as in the reference case, with slightly different times to equilibrium because of differences in growth rate.

[58] In summary, the rather constant aspect ratio as observed in Figure 12 might be linked to the parameter settings of the partial slip model (i.e., on coefficients $\beta_{1}$ and $\beta_{2}$ ). Variations in the resistance parameter yield variations in the dune aspect ratio, however, dune lengths, dune heights and times to equilibrium do not agree with the measurements in 
Table 3. Sensitivity Analysis of the Model Results for Changing Calibration Coefficients of the Partial Slip Model (Case 1) and Deviations From the Fastest-Growing Wavelength (Case 2)

\begin{tabular}{ccccccc}
\hline Case $^{\mathrm{a}}$ & $\beta_{2}$ & $\beta_{1}$ & $\mathrm{FGM}^{\mathrm{b}}(\mathrm{m})$ & $\lambda_{\mathrm{e}}^{\mathrm{c}}(\mathrm{m})$ & $\Delta_{\mathrm{e}}(\mathrm{m})$ & $\Delta_{\mathrm{e}} / \lambda_{\mathrm{e}}$ \\
\hline ref & 0.50 & 0.50 & 1.049 & $1.049(1.0)$ & 0.049 & 0.047 \\
1a & 0.25 & 0.64 & 2.621 & $2.621(1.0)$ & 0.075 & 0.029 \\
1b & 0.50 & 0.51 & 1.054 & $1.054(1.0)$ & 0.049 & 0.047 \\
$1 \mathrm{c}$ & 1.00 & 0.46 & 0.566 & $0.566(1.0)$ & 0.031 & 0.054 \\
$1 \mathrm{~d}$ & 2.00 & 0.44 & 0.376 & $0.376(1.0)$ & 0.023 & 0.061 \\
2a & 0.50 & 0.50 & 1.049 & $0.632(0.6)$ & 0.016 & 0.025 \\
2b & 0.50 & 0.50 & 1.049 & $0.843(0.8)$ & 0.039 & 0.047 \\
2c & 0.50 & 0.50 & 1.049 & $1.265(1.2)$ & 0.059 & 1.3 \\
2d & 0.50 & 0.50 & 1.049 & $1.476(1.4)$ & 0.069 & 0.047 \\
\hline
\end{tabular}

${ }^{a}$ For parameters see Table 2; for each simulation, the initial dune height is equal (i.e., $\Delta_{i}=0.1 D_{50}$ ).

${ }^{\mathrm{b}} \mathrm{FGM}$ is the fastest-growing wavelength found from linear stability analysis.

${ }^{\mathrm{c}}$ Here $\lambda_{\mathrm{e}}$ is the wavelength used in a simulation and the fraction $\lambda_{\mathrm{e}} / \mathrm{FGM}$ is given in parentheses.

those cases. Therefore, the setting $\beta_{1}=\beta_{2}=0.5$ seems to reproduce the experimental conditions most accurately.

[59] Figure 13a shows that the initially fastest-growing wavelength $\left(\lambda_{\text {fgm }}\right)$ depends linearly on the initial average water depth $h_{\mathrm{i}}$ for the specific flow conditions. More precisely, $\lambda_{\text {fgm }} \approx 7 h_{\mathrm{i}}$. In our simulations, the dune length does not vary, thus the initial fastest-growing wavelength is also the dune length in equilibrium $\left(\lambda_{\mathrm{e}}\right)$. However, since the water depth increases toward equilibrium, $\lambda_{\mathrm{e}} \approx 6 h_{\mathrm{e}}$. This is in agreement with various previous studies [e.g., Yalin, 1972; Van Rijn, 1984; Julien and Klaassen, 1995]. It turns out that for increasing dune length, the equilibrium dune height increases as well (Figure 13a). In effect, the dune aspect ratio remains almost constant at $\sim 0.047$, as was also observed in section 5.4. This is in line with the numerical experiments of Andreotti et al. [2002] who showed that both aeolian dune height and length are linked to the dune size, and that the dune aspect ratio becomes asymptotically constant for sufficiently large dune size.
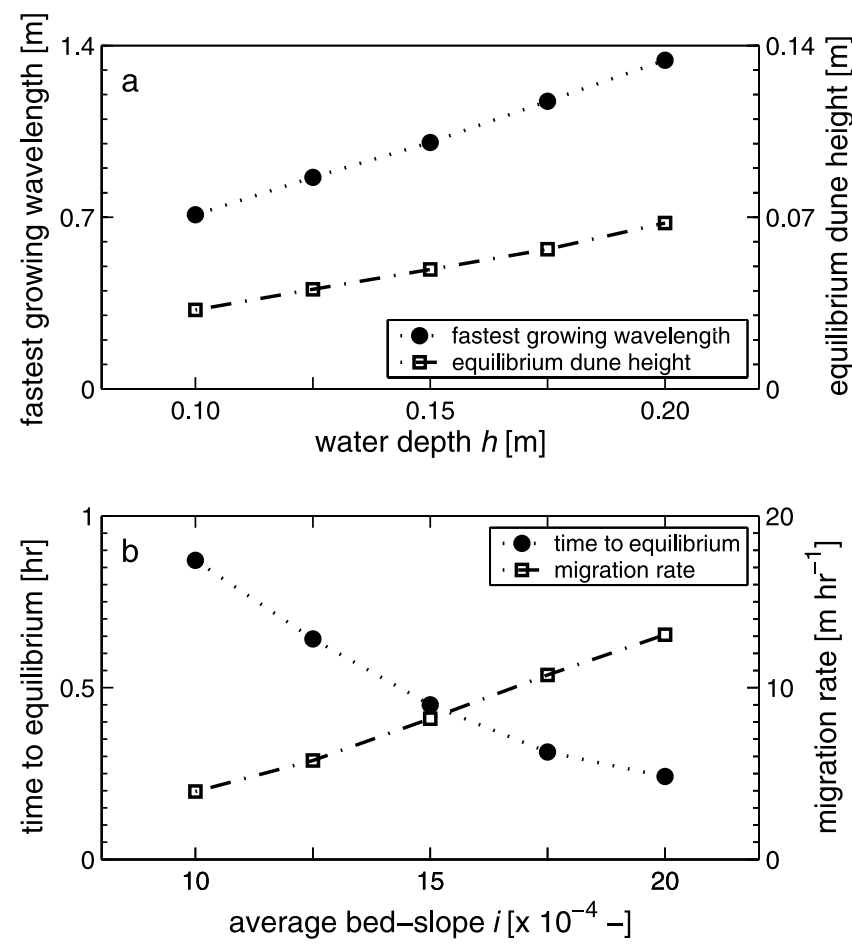

Figure 13. Sensitivity analysis for flow parameters.
[60] An increasing flume slope, and thus Froude number (if the flow depth remains constant), has a significant effect on the timescales of dune evolution (Figure 13b). If the flume slope increases for constant water depth, the flow velocities and bed shear stresses increase. The migration rate increases almost linearly with the slope, whereas the time to equilibrium decreases for increasing slope. In contrast, an increasing flume slope does not influence dune dimensions (not shown). This can be understood as follows. The fastest-growing wavelength found from linear stability analysis is controlled by displacements between the position of the maximum flux with respect to the dune crest (section 4). A changing slope does only influence the magnitude of the turbulence-averaged shear stress and not the distribution over a dune; therefore, the fastest-growing wavelength does not depend on the channel slope. In summary, the water depth is the only flow parameter that is able to alter the fastest-growing wavelength, and thus dune dimensions. The channel slope influences times to equilibrium and migration rates.

[61] Besides the bed shear stress, several parameters control the sediment flux (equation (8)), and thus dune formation. The proportionality constant $m$ has no influence on equilibrium dune dimensions (not shown), since it is a linear parameter in the sediment transport equation and does not change the fastest-growing wavelength. In contrast, it has an effect on the timescales of dune evolution (Figure 14) because of increased sediment fluxes. The median grain size $D_{50}$ influences the magnitude of the critical bed shear stress (equation (11)); as a result, the fastest-growing wavelength slightly increases for increasing grain size (not shown). Figure $14 \mathrm{~b}$ shows that for increasing sediment grain size, the time to equilibrium slightly increases, while the migration rate decreases.

[62] The influence of parameter $n$ in the sediment transport equation on model results is complicated, since its influence is nonlinear. Using experimental observations this parameter is estimated at $\sim 1.5$ [Wong and Parker, 2006]. Small variations in $n$ have a strong influence on both the equilibrium dimensions and the timescales of dune evolution. For $n=1.75$ (i.e., $+17 \%$ ), the fastest-growing wavelength decreases by about $10 \%$ compared to the reference simulation and the equilibrium dune height decreases by $20 \%$. This means that the dune aspect ratio decreases by about $11 \%$, which can be understood as follows. The separation criterion is based on the maximum slope of the dune lee. Because of the nonlinear influence of $n$, not only the fastest-growing wavelength is altered, but also the dune shape at the moment that flow 

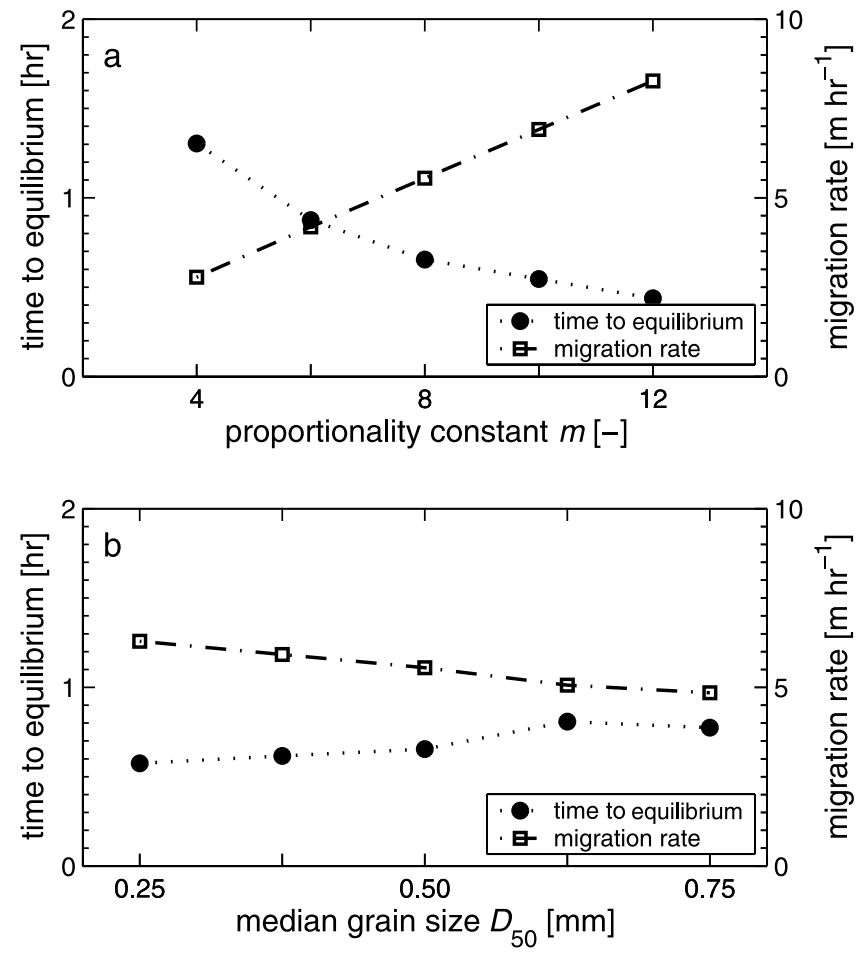

Figure 14. Sensitivity analysis for parameters in sediment transport formula.

separation sets in is likely to be different from that in the reference situation. Therefore, dune evolution after flow separation sets in is different, and a different aspect ratio is obtained. The migration rate decreases by $\sim 75 \%$ for $n=1.75$ compared to the reference case. A decreased value of $n=1.25$ has the opposite effect as described above.

[63] In the model, the critical angle of flow separation is $-10^{\circ}$ and the angle of repose is $-30^{\circ}$. Varying these parameters by $\pm 30 \%$, has no effect on equilibrium dune dimensions and timescales of dune evolution. The parameter $\tau_{\mathrm{A}}$, representing the gradient in the bed shear stress in case of flow separation at the flow reattachment point (equation (14)), was estimated as $\tau_{\mathrm{A}}=2$. Varying $\tau_{\mathrm{A}}$ between 1.5 and 2.5 , does not influence the qualitative behavior of dune formation, but equilibrium dune dimensions and timescales of dune evolution are sensitive to this parameter. A value of $\tau_{\mathrm{A}}=1.5$ yields $10 \%$ lower dunes, while a value of $\tau_{\mathrm{A}}=2.5$ yields $11 \%$ higher dunes compared to the reference simulation. For increasing values of $\tau_{\mathrm{A}}$ the erosion rates over the stoss side of the dunes increases, yielding higher dunes and slightly larger bed slopes at the stoss side.

\section{Discussion}

[64] A sensitivity analysis has shown that, apart from the calibration coefficients $\beta_{1}$ and $\beta_{2}$, the water depth mainly controls predicted dune dimensions. This is because the water depth is introduced as a scaling length in both the relationship for the eddy viscosity and bed resistance parameter. As a result, the initially fastest-growing wavelength is strongly linked to the initial water depth. The initial dune height is much smaller than the fastest-growing wavelength, since it depends on the grain size. Therefore, the dune length controls bed gradients and convergence and divergence of sediment fluxes along a dune, eventually setting the equilibrium dune height. The channel slope and parameters of the sediment transport equation mainly influence times to equilibrium and migration rates. This emphasizes the importance of correct estimation of the value of $m$, if one is interested in timescales of bed form evolution. Also the value of $n$ is important, since it influences both dune shapes and equilibrium dimensions. Model results are shown not to depend on the choice of the flow separation criterion and angle of repose. In contrast, model results are sensitive to subtle changes in the parameterized bed shear stress distribution over the stoss side of a dune.

[65] Similar to earlier stability models [e.g., Smith, 1970; Engelund, 1970], the flow model employs a constant eddy viscosity $\left(A_{\mathrm{v}}\right)$ over the flow depth as turbulence closure, which is a crude approximation of reality. In line with Engelund [1970], we do not expect that a more sophisticated turbulence closure would yield fundamental changes to the results. However, a sensitivity analysis has shown that the fastest-growing wavelength is rather sensitive to the choice of the calibration coefficients $\beta_{1}$ and $\beta_{2}$ (section 5.5). For increasing values of the resistance parameter $S$ (i.e., near-bed velocity decreases and velocity gradient increases, and in the limit of $S \rightarrow \infty$ this amounts to a no slip condition), shorter waves are found, which evolve faster to an equilibrium. The quantitative comparison of the model results against flume experiments (section 5.4) shows that dune dimensions are predicted reasonably well with $\beta_{1}=\beta_{2}=0.5$. Thus, at least for flume conditions, the calibrated values are believed to yield realistic velocity profiles and bed shear stresses.

[66] The same partial slip condition is applied over the separation streamline as is done over the bed in the region outside the flow separation zone. Partly this is physical, since at the upper boundary of the flow separation zone, there exists a (downstream) velocity. However, it might be nonphysical that the boundary condition is the same as outside the region of flow separation. Mixing patterns in the flow separation zone influence the eddy viscosity just above it, which could be included as a direct influence on the eddy viscosity. However, not much influence is expected on dune dimensions and shapes, since the boundary stresses computed over the flow separation zone are not used to evaluate sediment transport rates; the separation streamline and partial slip condition are only needed to treat the flow as hydrostatic.

[67] In the presented morphodynamic model, bed load sediment transport is evaluated using the turbulence-averaged bed shear stress as flow parameter. Nelson et al. [1995] argued that this is not accurate in case of nonuniform flow with developing boundary layers associated with significant spatial variations in turbulence structures, as is the case with dunes [e.g., McLean et al., 1994; Nelson et al., 1995; Fernandez et al., 2006]. Nelson et al. [2005] and Giri and Shimizu [2006] realistically simulated dune morphodynamics using a stochastic sediment transport model taking fluctuations of the bed shear stress on turbulent timescales into account. On the other hand, Tjerry and Fredsøe [2005] obtained realistic dune shapes, by relating sediment transport to the turbulence-averaged bed shear stress. In the chosen model setup, we are unable to predict all details of sediment transport related to turbulent fluctuations, but the general pattern of dune evolution can be evaluated with sufficient 
accuracy with relatively few computational effort, which is an advantage for practical applications.

[68] During a simulation, the dune length remains constant. This is because the initial profile is a uniform sinusoidal disturbance and the employed periodic boundary conditions constrain the final dune length to the initial one. Similar to Giri and Shimizu [2006] and Van den Berg [2007], we could introduce a spectrum of disturbances as initial condition. Model simulations with such a condition have shown that bed forms with different migration velocities merge, quickly giving rise to the fastest-growing wavelength as found from a linear analysis. After that, dunes keep merging until one dune covers the domain, which obviously is unrealistic. A combination of periodic boundary conditions (both for flow and sediment transport) and the approach to use a turbulenceaveraged bed shear stress to drive the sediment transport does not allow for new crests in the domain. Improvements regarding this issue could imply switching to nonperiodic boundary conditions and a more sophisticated turbulence and sediment transport model. However, since the actual process of how the dune length is obtained over time is not of central interest in this paper, the simulation model determines the (constant) dune length from a numerical linear stability analysis. This approach strongly reduces the required computational effort to simulate dunes from small amplitude toward saturated steady state dunes.

[69] Once the flow begins to separate the physics of the transport process changes greatly and presumably the fastestgrowing wavelength changes significantly. This is not incorporated in the model, because of periodic boundary conditions and the coupling between the flow solution and parameterized bed shear stress distribution in the case of flow separation. The approach to use a separation bubble was introduced for the aeolian case, which is different from the fluvial case. It may be necessary to include more of the effects of flow separation than has been done in the presented morphodynamic model. Moreover, the parameterization of flow separation introduces a nonlinear feedback mechanism to the flow, while the flow equations contain nonlinear convective terms. This might introduce an inconsistency which is not present if the convective terms are linearized around the mean profile obtained in the absence of bed forms. These aspects remain for future research.

\section{Conclusions}

[70] The new morphodynamic model presented in this paper is able to realistically simulate river dune evolution. During their evolution, initially symmetric dunes evolve into asymmetrical dunes with flow separation over angle-of-repose leesides. For a correct estimation of the fastest-growing wavelength, bed slope effects are essential, since they influence the location of the maximum sediment flux with respect to the dune crest. For evolution toward equilibrium, the inclusion of flow separation is essential since without flow separation dunes saturate at an early stage of evolution, leading to both an incorrect dune shape without a slip face and an underprediction of dune height and time to equilibrium.

[71] Characteristic dune parameters, such as dune height, dune length, dune aspect ratio and migration rate compare reasonably well to dunes in flume experiments. The initial dune length which is found from a numerical linear stability analysis agrees quite well with measured dune lengths in equilibrium, indicating that this length is probably not influenced by flow separation. Model results show that dune dimensions such as height and length are mainly controlled by the average flow depth. Timescales of bed form evolution, however, are mainly controlled by the channel slope and the sediment transport rate. Therefore, it is very important to have reliable estimates of the empirical coefficients that are used to determine the sediment transport rate.

[72] Using the proposed parameterization of flow separation avoids the necessity of computing the complicated processes related to flow separation, saving a lot of computational effort. The model forms a promising framework for future research, since it can be applied to river flood waves, to yield fast and reliable estimates of dune dimensions, and associated resistance to flow.

[73] Acknowledgments. This work is supported by the Technology Foundation STW, the applied science division of NWO, and the technology program of the Ministry of Economic Affairs (project 06222). Joris Van den Berg and Ruud Van Damme provided us with the flow model code and helped in setting up the model, for which we are very grateful. We thank Jeremy Venditti and Stephen Coleman for providing very useful data. We also want to thank Ralph Schielen for his constructive comments on earlier drafts of the manuscript. Finally, we thank the reviewers Stephen McLean, Attila Németh, and the anonymous reviewer.

\section{References}

Allen, J. R. L. (1968), Current Ripples: Their Relation to Patterns of Water and Sediment Motion, North-Holland, Amsterdam.

Andreotti, B., P. Claudin, and S. Douady (2002), Selection of dune shapes and velocities. Part 2: A two-dimensional modelling, Eur. Phys. J. B, 28 , 341-352, doi:10.1140/epjb/e2002-00237-3.

Azad, R. S. (1996), Turbulent flow in a conical diffuser: A review, Exp. Thermal Fluid Sci., 13, 318-337.

Bennett, S. J., and J. L. Best (1995), Mean flow and turbulence structure over fixed, two-dimensional dunes: Implications for sediment transport and bedform stability, Sedimentology, 42, 491-513.

Besio, G., P. Blondeaux, M. Brocchini, and G. Vittori (2004), On the modeling of sand wave migration, J. Geophys. Res., 109, C04018, doi:10.1029/2002JC001622.

Best, J. (2005), The fluid dynamics of river dunes: A review and some future research directions, J. Geophys. Res., 110, F04S02, doi:10.1029/ 2004JF000218

Best, J., and R. Kostaschuk (2002), An experimental study of turbulent flow over a low-angle dune, J. Geophys. Res., 107(C9), 3135, doi:10.1029/ 2000JC000294.

Blom, A., J. S. Ribberink, and H. J. de Vriend (2003), Vertical sorting in bed forms: Flume experiments with a natural and a trimodal sediment mixture, Water Resour. Res., 39(2), 1025, doi:10.1029/2001WR001088.

Carling, P. A., J. J. Williams, E. Gölz, and A. D. Kelsey (2000), The morphodynamics of fluvial sand dunes in the River Rhine, near Mainz, Germany. II. Hydrodynamics and sediment transport, Sedimentology, 47, 253-278, doi:10.1046/j.1365-3091.2000.00291.x.

Charru, F. (2006), Selection of the ripple length on a granular bed sheared by a liquid flow, Phys. Fluids, 18, 121508, doi:10.1063/1.2397005.

Coleman, S. E., M. H. Zhang, and T. M. Clunie (2005), Sediment-wave development in subcritical water flow, J. Hydraul. Eng., 131(2), 106111, doi:10.1061/(ASCE)0733-9429(2005)131:2(106).

Coleman, S. E., V. I. Nikora, S. R. McLean, T. M. Clunie, T. Schlicke, and B. W. Melville (2006), Equilibrium hydrodynamics concept for developing dunes, Phys. Fluids, 18, 105104, doi:10.1063/1.2358332.

Dodd, N., P. Blondeaux, D. Calvete, H. E. de Swart, A. Falques, S. J. M. H. Hulscher, G. Rozynski, and G. Vittori (2003), Understanding coastal morphodynamics using stability methods, J. Coastal Res., 19(4), 849-865.

Driegen, J. (1986), Flume experiments on dunes under steady flow conditions (uniform sand, $d_{\mathrm{m}}=0.77 \mathrm{~mm}$ ): Description of bed forms, Rep. 567 , WL Delft Hydraul., Delft, Netherlands.

Einstein, H. A., and N. L. Barbarossa (1952), River channel roughness, Trans. Am. Soc. Civ. Eng., 117, 1121-1146.

Engelund, F. (1966), Hydraulic resistance of alluvial streams, J. Hydraul. Div. Am. Soc. Civ. Eng., 92(2), 315-327.

Engelund, F. (1970), Instability of erodible beds, J. Fluid Mech., 42, $225-$ 
Exner, F. M. (1920), Zur Physik der Dünen (in German), Sitzungsber. Akad. Wiss. Wien, Abt. IIa, Band 129, Vienna.

Fernandez, R., J. Best, and F. López (2006), Mean flow, turbulence structure, and bed form superimposition across the ripple-dune transition, Water Resour. Res., 42, W05406, doi:10.1029/2005WR004330.

Fredsøe, J. (1974), On the development of dunes in erodible channels, J. Fluid Mech., 64, 1-16.

Fredsøe, J., and R. Deigaard (1992), Mechanics of Coastal Sediment Transport, Adv. Ser. Ocean Eng., vol. 3, 368 pp., World Sci., Singapore.

Friedrich, H., A. J. Paarlberg, and J. Lansink (2007), Evaluation of statistical properties of dune profiles, in Proceedings of the 5th IAHR Symposium on River, Coastal and Estuarine Morphodynamics, vol. 2, edited by C. M. Dohmen-Janssen and S. J. M. H. Hulscher, pp. 913-921, Taylor and Francis, London.

Giri, S., and Y. Shimizu (2006), Numerical computation of sand dune migration with free surface flow, Water Resour. Res., 42, W10422, doi:10.1029/2005WR004588.

Hersen, P. (2004), On the crescentic shape of barchan dunes, Eur. Phys. J. B, 37, 507-514

Hulscher, S. J. M. H. (1996), Tidal-induced large-scale regular bed form patterns in a three-dimensional shallow water model, J. Geophys. Res., $101,20,727-20,744$

Hulscher, S. J. M. H., and C. M. Dohmen-Janssen (2005), Introduction to special section on Marine Sand Wave and River Dune Dynamics, J. Geophys. Res., 110, F04S01, doi:10.1029/2005JF000404.

Hulscher, S. J. M. H., and G. M. van den Brink (2001), Comparison between predicted and observed sand waves and sand banks in the North Sea, J. Geophys. Res., 106, 9327-9338.

Jerolmack, D. J., and D. C. Mohrig (2005), A unified model for subaqueous bed form dynamics, Water Resour. Res., 41, W12421, doi:10.1029/ 2005WR004329.

Ji, Z.-G., and C. Mendoza (1997), Weakly nonlinear stability analysis for dune formation, J. Hydraul. Eng., 123(11), 979-985.

Julien, P. Y., and G. J. Klaassen (1995), Sand-dune geometry of large rivers during floods, J. Hydraul. Eng., 121(9), 657-663.

Julien, P. Y., G. J. Klaassen, W. B. M. Ten Brinke, and A. W. E. Wilbers (2002), Case study: Bed resistance of Rhine River during 1998 flood, J. Hydraul. Eng., 128(12), 1042-1050.

Kennedy, J. F. (1963), The mechanics of dunes and antidunes in erodiblebed channels, J. Fluid Mech., 16, 521-544.

Kostaschuk, R., and P. Villard (1996), Flow and sediment transport over large subaqueous dunes: Fraser River, Canada, Sedimentology, 43, 849863.

Kroy, K., G. Sauermann, and H. J. Herrmann (2002), Minimal model for aeolian sand dunes, Phys. Rev. E, 66(3), 031302, doi:10.1103/PhysRevE.66.031302.

Maas, L. R. M., and J. J. M. Van Haren (1987), Observations on the vertical structure of tidal and internal currents in the central North Sea, J. Mar. Res., 45, 293-318.

McLean, S. R., J. M. Nelson, and S. R. Wolfe (1994), Turbulence structure over two-dimensional bed forms: Implications for sediment transport, J. Geophys. Res., 99, 12,729-12,747.

Meyer-Peter, E., and R. Müller (1948), Formulas for bed-load transport, paper presented at 2nd Meeting, Int. Assoc. for Hydraul. Res., Stockholm.

Momiji, H., and S. R. Bishop (2002), Estimating the windward slope profile of a barchan dune, Sedimentology, 49, 467-481.

Nelson, J. M., R. L. Schreve, S. R. McLean, and T. Drake (1995), Role of near-bed turbulence structure in bedload transport and bedform mechanics, Water Resour. Res., 31(8), 2071-2086.

Nelson, J. M., A. R. Burman, Y. Shimizu, S. R. McLean, R. L. Shreve, and M. Schmeeckle (2005), Computing flow and sediment transport over bedforms, in Proceedings of the 4th IAHR Symposium on River, Coastal and Estuarine Morphodynamics, vol. 2, edited by G. Parker and M. H. Garcia, pp. 861-872, Taylor and Francis, London.

Németh, A. A., S. J. M. H. Hulscher, and R. M. J. Van Damme (2006), Simulating offshore sand waves, Coastal Eng., 53, 265-275, doi:10.1016/ j.coastaleng.2005.10.014

Németh, A. A., S. J. M. H. Hulscher, and R. M. J. Van Damme (2007), Modelling offshore sand wave evolution, Cont. Shelf Res., 27(5), 713728, doi:10.1016/j.csr.2006.11.010.

Niño, Y., A. Atala, M. Barahona, and D. Aracena (2002), Discrete particle model for analyzing bedform development, J. Hydraul. Eng., 128(4), 381-389, doi:10.1061/(ASCE)0733-9429(2002)128:4(381).

Ogink, H. J. M. (1988), Hydraulic roughness of bedforms, Rep. M2017, WL Delft Hydraul., Delft, Netherlands.

Onda, S., and T. Hosoda (2004), Numerical simulation on development process of dunes and flow resistance, in River Flow 2004, vol. 1, edited by M. Greco, A. Carravetta, and R. Della Morte, pp. 245-252, A. A. Balkema, Leiden, Netherlands.

Paarlberg, A. J. (2008), Modelling dune evolution and dynamic roughness in rivers, Ph.D. thesis, Univ. of Twente, Enschede, Netherlands.
Paarlberg, A. J., C. M. Dohmen-Janssen, S. J. M. H. Hulscher, and P. Termes (2007), A parameterization of flow separation over subaqueous dunes, Water Resour. Res., 43, W12417, doi:10.1029/2006WR005425.

Parsons, D. R., J. L. Best, O. Orfeo, R. J. Hardy, R. Kostaschuk, and S. N. Lane (2005), Morphology and flow fields of three-dimensional dunes, Rio Paraná, Argentina: Results from simultaneous multibeam echo sounding and acoustic Doppler current profiling, J. Geophys. Res., 110, F04S03, doi:10.1029/2004JF000231.

Prandle, D. (1982), The vertical structure of tidal currents and other oscillatory flows, Cont. Shelf Res., 1(2), 191-207.

Raudkivi, A. J. (1963), Study of sediment ripple formation, J. Hydraul. Div. Am. Soc. Civ. Eng., 89(6), 15-33.

Richards, K. J. (1980), The formation of ripples and dunes on an erobible bed, J. Fluid Mech., 99, 597-618.

Sauermann, G., J. S. Andrade Jr., L. P. Maia, U. M. S. Costa, A. D. Araújo, and H. J. Herrmann (2003), Wind velocity and sand transport on a barchan dune, Geomorphology, 54, 245-255.

Schramkowski, G. P., and H. E. de Swart (2002), Morphodynamic equilibrium in straight tidal channels: Combined effects of the Coriolis force and external overtides, J. Geophys. Res., 107(C12), 3227, doi:10.1029/ 2000JC000693.

Schwämmle, V., and H. J. Herrmann (2004), Modelling transverse dunes, Earth Surf. Processes Landforms, 29, 769-784.

Sekine, M., and G. Parker (1992), Bed-load transport on transverse slope, J. Hydraul. Eng., 118(4), 513-535.

Sharp, R. P. (1963), Wind ripples, J. Geol., 71, 617-636.

Smith, J. D. (1970), Stability of a sand bed subjected to a shear flow of low Froude number, J. Geophys. Res., 75, 5928-5940.

Smith, J. D., and S. R. McLean (1977), Spatially-averaged flow over a wavy surface, J. Geophys. Res., 82, 1735-1746.

Soulsby, R. L. (1990), Tidal-current boundary layers, in The Sea, vol. 9, Ocean Engineering Science, edited by B. Le Méhauté and D. M. Hanes, pp. 523-566, John Wiley, New York.

Sumer, B. M., L. H. C. Chua, N. S. Cheng, and J. Fredsøe (2003), Influence of turbulence on bed load sediment transport, J. Hydraul. Eng., 129(8), 585-596, doi:10.1061/(ASCE)0733-9429(2003)129:8(585).

Ten Brinke, W. B. M., A. W. E. Wilbers, and C. Wesseling (1999), Dune growth, decay and migration rates during a large-magnitude flood at a sand and mixed sand-gravel bed in the Dutch Rhine River system, Spec. Publ. Int. Assoc. Sedimentol., 28, 15-32.

Tjerry, S., and J. Fredsøe (2005), Calculation of dune morphology, J. Geophys. Res., 110, F04013, doi:10.1029/2004JF000171.

Van den Berg, J. (2007), Non-linear sand wave evolution, Ph.D. thesis, Univ. of Twente, Enschede, Netherlands.

Van den Berg, J., and R. Van Damme (2005), Sand wave simulation on large domains, in Proceedings of the 4th IAHR Symposium on River, Coastal and Estuarine Morphodynamics, vol. 2, edited by G. Parker and M. H. Garcia, pp. 991-997, Taylor and Francis, London.

Van der Mark, C. F., A. Blom, and S. J. M. H. Hulscher (2007), Variability in bedform characteristics using flume and river data, in Proceedings of the 5th IAHR Symposium on River, Coastal and Estuarine Morphodynamics, vol. 2, edited by C. M. Dohmen-Janssen and S. J. M. H. Hulscher, pp. 923-930, Taylor and Francis, London.

Vanoni, V. A., and L. S. Hwang (1967), Relation between bed forms and friction in streams, J. Hydraul. Div. Am. Soc. Civ. Eng., 93, 121-144.

Van Rijn, L. C. (1984), Sediment transport, part III: Bed forms and alluvial roughness, J. Hydraul. Eng., 110(12), 1733-1754.

Van Rijn, L. C. (1993), Principles of Sediment Transport in Rivers, Estuaries and Coastal Seas, 335 pp., Aqua, Amsterdam.

Venditti, J. G. (2003), Initiation and development of sand dunes in river channels, Ph.D. thesis, Univ. of British Columbia, Vancouver, B. C., Canada

Venditti, J. G., M. A. Church, and S. J. Bennett (2005), Bed form initiation from a flat sand bed, J. Geophys. Res., 110, F01009, doi:10.1029/ 2004JF000149.

Vittal, N. (1972), Flow over triangular roughnesses in open channels, Ph.D. thesis, Univ. of Roorkee, Roorkee, India.

Vreugdenhil, C. B. (1994), Numerical Methods for Shallow-Water Flow, Kluwer Acad, Dordrecht, Netherlands.

Walker, I. J., and W. G. Nickling (2002), Dynamics of secondary airflow and sediment transport over and in the lee of transverse dunes, Prog. Phys. Geogr., 26(1), 47-75, doi:10.1191/0309133302pp325ra.

Wijbenga, J. H. A. (1990), Flow resistance and bedform dimensions for varying flow conditions: A literature review (main text and annexes), Rep. Q785, WL Delft Hydraul., Delft, Netherlands.

Wong, M., and G. Parker (2006), Reanalysis and correction of bed-load relation of Meyer-Peter and Müller using their own database, J. Hydraul. Eng., 132(11), 1159-1168, doi:10.1061/(ASCE)0733-9429(2006)132: 11(1159)

Yalin, M. S. (1972), Mechanics of Sediment Transport, Pergamon, New York. 
Yamaguchi, S., and N. Izumi (2002), Weakly nonlinear stability analysis of dune formation, in River Flow 2002, edited by D. Bousmar and Y. Zech, pp. 843-850, Swets and Zeitlinger, Lisse, Netherlands.

Zeman, O., and N. O. Jensen (1987), Modification of turbulence characteristics in flow over hills, Q. J. R. Meteorol. Soc., 113(475), 55-80.
Zhou, D., and C. Mendoza (2005), Growth model for sand wavelets, J. Hydraul. Eng., 131(10), 866-876, doi:10.1061/(ASCE)07339429(2005)131:10(866).

C. M. Dohmen-Janssen and S. J. M. H. Hulscher, Department of Water Engineering and Management, University of Twente, Horst Building, P.O. Box 217, NL-7500 AE, Enschede, Netherlands.

A. J. Paarlberg and P. Termes, HKV Consultants, P.O. Box 2120, NL8203 AC, Lelystad, Netherlands. (andries.paarlberg@hotmail.com) 